Florida International University FIU Digital Commons

3-26-2010

\title{
Assessment of nutritional status of patients on hemodilaysis: a single center study from Jeddah, Saudi Arabia.
}

Khadija A. Alharbi

Florida International University, kalha001@fiu.edu

DOI: $10.25148 /$ etd.FI10041637

Follow this and additional works at: https://digitalcommons.fiu.edu/etd

Part of the Dietetics and Clinical Nutrition Commons

\section{Recommended Citation}

Alharbi, Khadija A., "Assessment of nutritional status of patients on hemodilaysis: a single center study from Jeddah, Saudi Arabia." (2010). FIU Electronic Theses and Dissertations. 178.

https://digitalcommons.fiu.edu/etd/178 


\title{
FLORIDA INTERNATIONAL UNIVERSITY \\ Miami, Florida
}

\section{ASSESSMENT OF NUTRITIONAL STATUS OF PATIENTS ON HEMODIALYSIS: A SINGLE CENTER STUDY FROM JEDDAH, SAUDI ARABIA}

\author{
A thesis submitted in partial fulfillment of the \\ requirements for the degree of \\ MASTER OF SCIENCE \\ in \\ DIETETICS AND NUTRITION \\ by
}

Khadija Alharbi

2010 
To: Dean Fernando M. Treviño

R.Stempel College of Public Health and Social Work

This thesis, written by Khadija Alharbi, and entitled Assessment of Nutritional Status of Patients on Hemodialysis: A Single Center Study from Jeddah, Saudi Arabia, having been approved in respect to style and intellectual content, is referred to you for judgment.

We have read this thesis and recommend that it be approved.

Adriana Campa

Victoria Castellanos

Evelyn B. Enrione, Major Professor

Date of Defense: March 26, 2010

The thesis of Khadija Alharbi is approved.

Dean Fernando M. Treviño

R.Stempel College of Public Health and Social Work

Interim Dean Kevin O'Shea

University Graduate School

Florida International University, 2010 


\section{DEDICATION}

I dedicate this thesis to my daughter, Sereen, with a hope that she would one day realize that education is a "weapon" to fight ignorance and a key to open doors for success. 


\section{ACKNOWLEDGMENTS}

I am heartily thankful to my professor, Evelyn Enrione, whose encouragement, guidance and support from the initial to the final level enabled me to develop an understanding of the thesis. Dr. Enrione always has been supportive not only in the research field, but also in the academic field. Also, it is a pleasure to thank Dr. Victoria Castellanos, Dr. Adriana Campa, and Dr. Paulette Johnson who made this thesis possible.

Lastly, I offer my regards and blessings to all of those who supported me in any respect during the completion of the thesis. 


\section{ABSTRACT OF THE THESIS \\ ASSESSMENT OF NUTRITIONAL STATUS OF PATIENTS ON HEMODIALYSIS: \\ A SINGLE CENTER STUDY FROM JEDDAH, SAUDI ARABIA}

by

Khadija Alharbi

Florida International University, 2010

Miami, Florida

Professor Evelyn Enrione, Major Professor

Malnutrition (MN) is prevalent worldwide in hemodialysis patients

(HDP); however it has not been assessed in HDP living in Jeddah, Saudi Arabia. The purpose of this study was to estimate the prevalence of MN in HDP at the Jeddah Kidney Center as well as to determine if the 7-point subjective global assessment (SGA) correlates with anthropometric [Body Mass Index (BMI), Tricep Skinfold Thickness (TSF), Mid-Arm Muscle Circumference (MAMC)], or biochemical (albumin) measurements. In a cross sectional, descriptive study, 270 HDP were assessed for MN. Over half of the HDP were malnourished, with $47.8 \%$ moderately and $6.3 \%$ severely malnourished. Fifty-eight percent of HDP did not adhere to their diet prescription. As albumin, BMI, TSF, and MAMC decreased, malnutrition became more severe $(\mathrm{p}<.01)$. Patients who were female $(\mathrm{OR}=.43, \mathrm{p}=.001)$, older $(\mathrm{OR}=.45, \mathrm{p}=.001)$, with no education $(\mathrm{OR}=3.10, \mathrm{p}=.001)$, underweight $(\mathrm{OR}=3.56, \mathrm{p}<.001)$, small TSF $(\mathrm{OR}=1.12, \mathrm{p}=.001)$, and small MAMC $(\mathrm{OR}=1.15, \mathrm{p}=.001)$ were more likely to be malnourished. The prevalence 
of $\mathrm{MN}$ is high in these HDP. A consistent nutritional assessment protocol is warranted and should be implemented to decrease MN in Saudi HDP.

\section{TABLE OF CONTENTS}

\section{CHAPTER}

PAGE

\section{INTRODUCTION}

II. LITERATURE REVIEW

Malnutrition in Hemodialysis in Americas, Europe, and Western Pacific Regions

Malnutrition in Hemodialysis in Eastern Mediterranean and South

East Asia Regions

$\begin{array}{lr}\text { III. METHODS } & 18\end{array}$

$\begin{array}{lr}\text { Subjects } & 18\end{array}$

$\begin{array}{ll}\text { Protocol } & 19\end{array}$

Assessment Instruments \& Measures $\quad 20$

$\begin{array}{ll}\text { Statistical Analysis } & 24\end{array}$

IV. RESULTS 25

Subject Demographics $\quad 25$

Diet and Fluid Prescription and Deviation 25

$\begin{array}{ll}\text { Prevalence of Malnutrition } & 26\end{array}$

V. DISCUSSION 33

Conclusion $\quad 39$

$\begin{array}{ll}\text { LIST OF REFERENCES } & 40\end{array}$

APPENDICES 


\section{LIST OF TABLES}

TABLE

PAGE

1. Demographic characteristics of hemodialysis patients at the Jeddah Kidney Center, Jeddah, Saudi Arabia (n=270)

2. Presence of co-morbidities in hemodialysis patients at the Jeddah Kidney Center, Jeddah, Saudi Arabia ( $\mathrm{n}=217)$

3. Self-reported deviation from diet prescription and fluid restriction of Hemodialysis patients at the Jeddah Kidney Center, Jeddah, Saudi Arabia $(\mathrm{n}=270)$

4. Percent of hemodialysis patients who are either nourished or malnourished according to the Subjective Global Assessment at the Jeddah Kidney Center in Jeddah, Arabia Saudi $(n=270)$

5. Nutritional status difference between genders according to the 7-point Subjective Global Assessment at the Jeddah Kidney Center, Jeddah, Saudi Arabia $(n=270)$

6. Nutritional status difference between younger $(<55$ years old $)$ and older ( $\geq 55$ years old) hemodialysis patients according to the 7-point Subjective Global Assessment at the Jeddah Kidney Center, Jeddah, Saudi Arabia $(\mathrm{n}=270)$

7. Comparison of albumin, body mass index, tricep skin-fold, mid-arm muscle circumference, and interdialytic weight gain between male and female hemodialysis patients at the Jeddah Kidney Center, Jeddah, Saudi Arabia $(n=270)$

8. Comparison of albumin, body mass index, tricep skin-fold, mid-arm muscle circumference, and interdialytic weight gain between hemodialysis patients aged $<55$ years old and $\geq 55$ years old at Jeddah Kidney Center, Jeddah, Saudi Arabia $(n=270)$ 


\section{LIST OF TABLES}

\section{TABLE}

PAGE

9. Albumin, body mass index, tricep skinfold, mid-arm muscle circumference, interdialytic weight gain, diet prescription deviation, or fluid restriction deviation correlated with the Subjective Global Assessment (well nourished, moderately malnourished, severely malnourished) for hemodialysis patients at Jeddah Kidney Center, Jeddah, Saudi Arabia $(n=270)$

10. Odds ratios of malnutrition by albumin, body mass index, tricep skin-fold, mid-arm muscle circumference, interdialytic weight gain, diet deviation, fluid deviation, gender, age, education, income, hemodialysis length or number of people in a household in hemodialysis patients at Jeddah Kidney Center, Jeddah, Saudi Arabia $(n=270)$ 


\section{INTRODUCTION}

Protein-energy malnutrition (PEM) is a relatively common problem, especially among adult patients with chronic renal disease who undergo hemodialysis (HDP). As the presence of PEM is one of the strongest predictors of morbidity and mortality in HDP, it is critical that dietitians accurately assess PEM in these patients. This is especially true in Saudi Arabia, where in 2006, 7,584 patients were treated with hemodialysis, a figure that is expected to exceed 11,000 in the end of 2010 (1). These HDP seem to have a tendency toward PEM, though it is not well documented (2-4). Appropriate and consistent assessment of PEM in Saudi Arabian HDP is rare because of the inconsistent methods applied in assessing PEM. Therefore, a method that could accurately and inexpensively detect PEM is warranted.

Several methods have been adapted to evaluate nutritional status in HDP for PEM, such as the subjective global assessment (SGA), anthropometric parameters, biochemical blood/urine values, bioelectrical impedance analysis (BIA) and dual energy x-ray absorptiometry. These methods vary from study to study due to ease of application, expense, availability, and practicality; however, a single, accepted best-practice method of PEM detection does not currently exist. While some techniques may work well in research situations, they are often not practical in clinical situations because they require expensive equipment or too much time. Therefore, this study offers a recommendation to detect PEM inexpensively by combining methods (e.g. SGA, anthropometric measures, and biochemical blood/urine values) in a clinical setting $(5,6)$. 
The goal of the study was to determine, with an inexpensive nutritional assessment protocol, the prevalence of PEM among HDP in a Saudi Arabian population at the Jeddah Kidney Center, located within the King Fahd General Hospital in Jeddah, Saudi Arabia. The protocol consisted of anthropometric measurements, a biochemical blood measurement, and the 7-point SGA. The hypotheses are: 1) high prevalence (>50\%) of malnutrition among adult HDP at the Center will be assessed; and, 2) there exists a significant correlation between the 7-point SGA and the anthropometric and biochemical measurements. 


\section{LITERATURE REVIEW}

Protein energy malnutrition is highly prevalent among HDP. Several studies assessed PEM in HDP by using single or combination of methods (2-4, 9, 12-26). However, a combination of valid and complementary methods should be performed to assess PEM in HDP, since a single method does not provide a complete indication of PEM status. Also, a combination of methods can measure PEM with greater sensitivity and specificity (5).

The National Kidney Foundation (NKF) recommends the SGA as one of the important methods to implement when assessing PEM in HDP. The SGA gives a comprehensive overview of nutritional intake and body composition including an approximate assessment of muscle and fat mass (7,8). Several SGA tools were developed since 1993 to assess PEM in HDP (9). This assessment instrument has evolved through a variety of different tools such as the original SGA, modified SGA (mSGA), 7-point SGA, dialysis malnutrition score (DMS), malnutrition inflammation score (MIS), and patient generated SGA (PG_SGA) $(7,8)$.

It was recommended that SGA be implemented with the core components of weight status, dietary intake, gastrointestinal symptoms, functional status, metabolic stress and a physical examination, as Detsky et al. implemented (10). The Canada-USA peritoneal dialysis research further improved the SGA to incorporate a numerical system to more accurately define malnutrition. In this method, a rating of seven indicates a well nourished status, while a rating of one indicates severe malnutrition. This method offers greater sensitivity when assessing PEM and a better predictive 
power in HDP (11).

The NKF also recommends the use of serum albumin since it is clinically valid in assessing PEM in HDP (5). Serum albumin is the most extensively studied serum protein. Studies involving patients with renal failure have established the connection between low levels of serum albumin and malnutrition $(2,3,9,14,17,18,21,23)$. Serum albumin indicates visceral protein status; therefore, measuring serum albumin with other nutritional assessment parameters is recommended (6).

Anthropometric measurements such as body mass index (BMI), tricep skinfold thickness (TSF) and mid-arm muscle circumference (MAMC), which have been used to assess nutritional status of patients on hemodialysis, are also valid and clinically useful indicators of PEM in HDP and they are recommended by the NKF. Various anthropometric measurements indicate different aspects of body composition; BMI and TSF denote body fat and mid-arm circumference (MAC) signifies muscle mass (fat free mass and somatic protein) $(5,7)$.

With the development of a variety of clinically sensitive measures to detect PEM, studies worldwide have been performed to determine the prevalence of PEM in HDP. Several studies suggest that the prevalence of malnutrition in HDP varies dramatically across the world, ranging from under $10 \%$ to over $90 \%(2-4,9,12-26)$.

One of the first studies that assessed PEM in HDP was completed in the late sixties with the majority of studies being conducted within the last three decades of the twentieth century. Most of the studies occurred in the developed countries of the Americas, Europe, and Western Pacific (9, 12-19). More recent studies have taken place in the developing countries of the Eastern Mediterranean and South East Asia regions. 


\section{Malnutrition in HDP in the Americas, Europe, and Western Pacific Regions}

A study conducted in the United Kingdom found the lowest occurrence of malnutrition. One hundred forty one HDP were evaluated using the 7 point SGA, anthropometric measurements including unintentional weight loss and BMI, and biochemical measurements including albumin. The nutritional status of HDP was detected by one of two methods, either 7-point SGA or unintentional weight loss in the past 6 months, BMI, and albumin. According to the SGA alone, only 13 patients $(9.2 \%)$ were malnourished. Including the other factors and disregarding the SGA, 41 of the participants (29\%) were classified as malnourished. The researchers concluded that SGA alone cannot provide a comprehensive nutritional assessment and should be used in conjunction with other methods such as albumin and BMI for the most accurate assessment (12). This study supports incorporating multiple techniques to assess nutritional status in HDP.

The studies in the United States of America and Australia also indicate low rates of malnutrition in HDP. The American study included 7,719 HDP from 145 different dialysis facilities. This study collected information including mSGA, BMI, albumin, lymphocyte count, creatinine, normalized protein catabolic rate (nPCR), neutrophil count, and bicarbonate. The mSGA is based on recent weight loss, physical appearance, and questions about appetite, nausea, energy level, and disease burden. According to the mSGA, researchers concluded that $7.6 \%$ were moderately malnourished and $11.0 \%$ of the HDP were severely malnourished (13). Although the study did not indicate more than one parameter to detect malnutrition, it did confirm that the mSGA is a tool for assessing 
malnutrition in HDP.

In Australia only 60 HDP participated in the study. The study used PG-SGA along with anthropometrics (BMI, TSF, weight loss in the past 6 months, and MAMC) and albumin to assess nutritional status. According to the PG-SGA, $80 \%$ of the HDP were well nourished, $20 \%$ of them were moderately malnourished and none were seriously malnourished. The study did not find any significant correlation between the PG-SGA and BMI, TSF or corrected arm muscle area. The researchers found a significant correlation between PG-SGA and percentage weight loss in the past 6 months $(\mathrm{r}=.56, \mathrm{p}<.001)$ and PG-SGA and serum albumin $(\mathrm{r}=-.28, \mathrm{p}<.038)(14)$. While many patients were not malnourished, the study did provide information indicating that the SGA may correlate with anthropometric parameters.

Studies completed in Italy, the Netherlands and Romania detected slightly higher percentages of malnutrition than the previous studies. The Italian study included 59 participants, 36 HDP and 23 continuous ambulatory peritoneal dialysis patients. The researchers assessed malnourishment using the original SGA, BIA, anthropometric (\% body fat, TSF, MAC and MAMC) and biochemical measurements (albumin, and nPCR). The original SGA was based on scoring five items (weight change, dietary intake, gastrointestinal symptoms, functional impairment, and physical examination). The HDP were then assigned a grade of well nourished (A), moderately malnourished (B), or severely malnourished (C) for each item. The study concluded that of the 59 participants, $18(30.5 \%)$ were malnourished, and of those four $(6.8 \%)$ were severely malnourished while $14(23.7 \%)$ were only moderately malnourished. The SGA was strongly correlated to albumin $(\mathrm{r}=-.51, \mathrm{p}<.001)$ and less strongly correlated to 
MAMC $(\mathrm{r}=-.28, \mathrm{p}=.028), \mathrm{nPCR}(\mathrm{r}=-.29, \mathrm{p}=.027)$ and $\%$ body fat $(\mathrm{r}=-.27, \mathrm{p}=$ .042) (9). This study establishes SGA as an effective means of estimating the nutritional status of HDP, since the results obtained from it, correlated with other objective measurements (anthropometric and biochemical measurements).

The Netherlands' study was implemented to test the reliability of the 7-point SGA when compared with biochemical [prealbumin, insulin-like growth factor 1 (IGF-1) and albumin] and anthropometric [BMI, \% body fat, MAC, and MAMC] measurements. Visser et al. assessed malnutrition in $22 \mathrm{HDP}$. Of the 22 patients who participated in the study, $9 \%$ were severely malnourished and $27 \%$ were mildly malnourished according to the 7-point SGA. The researchers also found significantly strong correlations between the 7-point SGA with the anthropometrics; BMI $(\mathrm{r}=.79, \mathrm{p}<.001), \%$ body fat $(\mathrm{r}=.77, \mathrm{p}<$ $.001)$, MAC $(\mathrm{r}=.71, \mathrm{p}<.001)$, MAMC $(\mathrm{r}=.38, \mathrm{p}=.09)$ and the biochemical measurements, prealbumin $(\mathrm{r}=.60, \mathrm{p}=.004)$, and IGF-1 $(\mathrm{r}=.44, \mathrm{p}=.047)(15)$. Thus, the 7-point SGA is a useful tool for assessing malnutrition within the HDP population, although the smaller sample size limits the strength of the correlations found between the biochemical measurements, anthropometric measurements, and the SGA values.

The nutritional status of 149 Romanian HDP was assessed with the original SGA; anthropometrics (BMI, MAC, TSF, MAMC); biochemical measurements [normalized equivalent of protein nitrogen appearance (nPNA), creatinine, albumin, cholesterol, hemoglobin and bicarbonate]; and BIA. The SGA indicated that $73 \%$ were well nourished and $27 \%$ of the HDP were mildly malnourished and no patient was severely malnourished. Well nourished patients were significantly younger than those who were mildly malnourished $(50.1$ versus 63.7 years; $p<.0001)(16)$. The result of 
the SGA associated significantly with age. The HDP who were $\geq 55$ years old had the worse nutritional status.

In Sweden and Brazil, the studies revealed greater than $50 \%$ of HPD were malnourished. The Swedish study included 128 HDP and assessed nutritional status with the subjective global nutritional assessment (SGNA). The SGNA includes six measurements: anorexia, vomiting, weight loss history, muscle wasting, edema, and subcutaneous fat. The study also collected anthropometrics [MAMC, \% body fat, and hand-grip strength (HGS)] and biochemical [hemoglobin, lymphocyte count, blood glucose, albumin, IGF-1, cholesterol, nPNA, creatinine and C-reactive protein (CRP)] measurements. According to the SGNA, 51\% of the HDP had mild malnutrition, and $13 \%$ had moderate or severe malnutrition. The SGNA scores correlated with the anthropometric and biochemical measurements, and the strongest correlation was with MAMC $(\mathrm{r}=-.64, \mathrm{p}<.001)$ and albumin $(\mathrm{r}=-.40, \mathrm{p}<.001)$. Also, SGNA correlated with age $(\mathrm{r}=-.27, \mathrm{p}<.01)(17)$. The correlations indicated that the SGNA along with anthropometric and biochemical measurements are necessary parameters in assessing malnutrition in HDP.

The Brazilian study assessed 44 HDP with the mSGA, biochemical measurements including albumin, total cholesterol, triglycerides, lymphocyte count, transferrin, ferritin, and CRP, anthropometric measurements including TSF, MAC, and BIA. Using these parameters, the mSGA revealed that $51 \%$ of HDP were mildly malnourished and $13 \%$ of the HDP were severely malnourished. The mSGA was positively correlated with age $(\mathrm{r}=$ $.30, \mathrm{p}=.02)$ as older adults were more malnourished and comorbidity $(\mathrm{r}=.33, \mathrm{p}=.02)$ and negatively correlated with each of the following parameters: BMI $(r=-.33, p=$ 
$.02)$, MAC $(\mathrm{r}=-.32, \mathrm{p}=.02), \operatorname{TSF}(\mathrm{r}=-.31, \mathrm{p}=.02)$, lymphocyte count $(\mathrm{r}=-.37, \mathrm{p}=$ $.02)$ and albumin $(r=-.45, \mathrm{p}=.02)$. However, many of those patients had BMI and albumin measurements within the optimal range (18). For this reason, this study found that SGA cannot function as a single malnutrition indicator because it does not always correlate with the biochemical and anthropometric measurements.

Serbia's study had the highest prevalence of malnutrition among HDP in the Americas, Europe and the Western Pacific regions. The nutritional status of 197 HDP were determined using the DMS, anthropometrics (BMI, TSF, MAC and MAMC) and biochemical (nPNA, hemoglobin, cholesterol, creatinine, and total protein) measurements. The DMS was based on scoring seven items (dietary intake, gastrointestinal symptoms, functional capacity, co-morbidity, weight change, subcutaneous fat, and signs of muscle wasting) on a five-point scale (1-normal to 5-very severe). The total DMS number could range from 7 (well nourished) to 35 (severely malnourished). According to the DMS, only 24 of the 197 HDP (12.2\%) were properly nourished, while $87.8 \%$ had some form of malnutrition. Correlations were not computed for DMS and anthropometric and biochemical measurements (19). This study demonstrates that PEM is prevalent in HDP and can be assessed with criteria similar to SGA. Among many factors, PEM has been identified as a major risk factor in HDP population in Serbia where the annual mortality rate of HDP is approximately $20 \%$.

The extensive research performed in the Americas, Europe, and Western Pacific has indicated that any form of the SGA cannot be used alone to assess malnutrition. The SGA needs to be applied in conjunction with anthropometric and biochemical parameters and perhaps bioelectrical impedance. These studies have provided insight into the 
methodology to assess PEM in HDP. Understanding these methods for assessment has assisted the Eastern Mediterranean and South East Asia regions in conducting research assessing PEM in HDP, as their research efforts did not start until the late 1990s (2-4, 20-26).

\section{Malnutrition in HDP in Eastern Mediterranean and South East Asia Regions}

Anees et al. found a relatively low rate of PEM in 51 Pakistani HDP. The nutritional status of the HDP was evaluated by using biochemical measurements (hemoglobin, hematocrit, blood urea nitrogen, serum albumin, total protein and lipid profile) and anthropometric measurements (BMI, MAC, TSF, and MAMC). Researchers used anthropometric measurements to classify the nutritional status of the patients as normal to mildly malnourished or moderately to severely malnourished. According to TSF, $37 \%$ of the HDP were moderately to severely malnourished while the MAMC indicated $39 \%$ were moderately to severely malnourished. The biochemical measurements, hemoglobin and hematocrit, were normal in seven patients and the rest were anemic. Serum albumin and total protein were normal in 30 patients with the other 21 hypoalbuminemic (20). The Pakistani study supported the previous findings that indicated anthropometrics and biochemical parameters are necessary to evaluate the nutritional status (somatic and visceral protein) of HDP.

In Iran, Afshar et al. showed a relatively low prevalence of PEM in HDP. The nutritional status of $54 \mathrm{HDP}$ was evaluated with different parameters such as the DMS as well as anthropometric measurements (TSF, MAC, MAMC, and BMI) and biochemical measurements [albumin, cholesterol, triglyceride, creatinine, blood urea nitrogen (BUN) and hematocrit]. Of the 54 patients assessed, 5.6\% of the HDP had severe malnutrition, 
$35.1 \%$ were mildly to moderately malnourished and $59.3 \%$ were well nourished. A significant correlation was found between the DMS score and the anthropometric measurements; TSF $(r=-.60, p<.01)$, MAC $(r=-.30, p=.02)$, MAMC $(r=-.34, p=$ $.01)$, BMI $(\mathrm{r}=-.34, \mathrm{p}=.02)$. The only biochemical parameter that correlated significantly with the DMS score was serum albumin $(r=-.32, \mathrm{p}=.02)$. Also, a significant correlation was not found between various age (24-64) and DMS $(r=-.03, p$ $=.80)(21)$. This research also confirms that a combination of methods (DMS, anthropometric and biochemical measurements) is recommended to indicate PEM in HDP.

A study in India included 81 patients who were divided into three groups. Group one was comprised of 27 patients with chronic renal insufficiency (CRI), group two consisted of 38 patients with end-stage renal disease (ESRD) on hemodialysis for at least 6 months, and group three was composed of 16 patients with continuous ambulatory peritoneal dialysis (CAPD). One measure to evaluate nutritional status was an SGA based on scoring seven items (weight change, dietary intake, gastrointestinal symptoms, functional state, subcutaneous fat, signs of muscle wasting and edema). Each item could be scored from 1-14 (well nourished), 15-35 (mild to moderately malnourished), to 36-49 (severely malnourished). Other measures included anthropometric measurements (BMI, TSF, MAC, MAMC), biochemical measurement (serum albumin), and a dietary recall in which the patients recounted their food consumption. Patients with CRI had the lowest frequency of malnutrition, with $48 \%$ being malnourished, while $50 \%$ of the patients with CAPD were malnourished. The HDP group had the highest percent of malnutrition, 58\%. Although the study did not report significant probability values, it indicated that the SGA 
was correlated to the anthropometric measurements, TSF $(r=.2)$, MAC $(r=.5)$, and MAMC $(r=.5)$, but not to dietary recall or serum albumin. The researchers did not provide correlation results for dietary recall and albumin (22). Even though, the Indian study showed various methods are needed to assess PEM in HDP.

Jordanian researchers had slightly different results. A study in 2007 was the first to determine the prevalence of malnutrition among HDP in Jordan. Tayyem et al. detected and compared PEM in males and females HDP using the original SGA, anthropometric (BMI, TSF, MAC, MAMC) and biochemical (albumin, total protein, hemoglobin, creatinine, urea, cholesterol, phosphorus, calcium, sodium, and potassium) measurements. Almost half of the female patients had some degree of malnutrition, as $41.5 \%$ were moderately malnourished and $7.4 \%$ were severely malnourished whereas, $72.6 \%$ of the males were moderately malnourished and $3.6 \%$ were severely malnourished. Also, the results showed that anthropometric measurements were decreased significantly $(\mathrm{p}<.001)$ in almost all SGA grades. Triceps skinfold thickness was significantly reduced in severely malnourished male HDP as compared to well and moderately malnourished. Hemoglobin decreased significantly with the increased malnutrition in both males $(p=.045)$ and females $(p=.005)$. Albumin $(p=.003)$ and total protein $(p=.016)$ were found to decrease significantly in male HDP only as malnutrition increased. Also, a significant difference $(\mathrm{p}=.001)$ was detected between male and female HDP in the original SGA grades, as a higher proportion of males (76.2\%) were malnourished when compared to $48.9 \%$ malnourished females (23).

In 2008, Tayyem and Mrayyan conducted another study in Jordan, where 180 HDP were assessed for PEM with the original SGA, anthropometric and biochemical 
measurements. The focus of the study was to compare patients treated and dialyzed at public hospitals to those at private hospitals. The researchers found that $61 \%$ and $63 \%$ in the private and public groups, respectively, were malnourished, either moderately or severely. The HDP who were treated in public hospitals weighed less and had a lower BMI when compared to the HDP who were treated in private hospitals. Also, phosphorus was the only biochemical measurement that differed between the two groups $(p=.001)$, an average value of $4.2 \mathrm{mg} / \mathrm{dL}$ for the private treatment group and an average of 5.1 $\mathrm{mg} / \mathrm{dL}$ for the public treatment group (24). Both Jordanian studies included several methods to assess PEM in HDP and brought attention that other cofactors such as gender and the quality of treatment could affect the nutritional status of HDP.

Yemen had the most malnourished patients. Basaleem et al. evaluated the nutritional status of $50 \mathrm{HDP}$ by using DMS, anthropometric measurements [interdialytic weight gain (IWG), BMI and mid-upper arm circumference (MUAC)] and biochemical measurements (urea, creatinine, hemoglobin, calcium, phosphorus, potassium, sodium, albumin, cholesterol, triglyceride, and blood sugar). Additionally, the patients were tested to determine their knowledge regarding which fruits and vegetables to avoid on a dialysis diet. Depending upon how many answers were correct they were scored satisfactory, acceptable or poor. The researchers determined that $100 \%$ of the 50 HDP were either mildly $(10 \%)$, moderately $(70 \%)$ or severely $(20 \%)$ malnourished. The only significant correlation was between the DMS and the anthropometric measurement, MUAC ( $p<$ $.05)$. Mid-upper arm circumference decreased as the degree of malnutrition increased from mild, moderate to severe. The biochemical measurements did not correlate with the DMS. When estimating the relative risk by odd ratio (OR) to determine the risk of 
malnutrition among HDP, the risk of malnutrition was 19 times higher among those with more than two kilograms IWG than those with lesser IWG (OR: 19.7, $p<.05$ ), also the risk of malnutrition was significantly four times higher among those $\geq 50$ years than their younger counterparts (OR: $4.10, \mathrm{p}<.05)$. Only $14 \%$ of HDP had satisfactory knowledge score about fruits and vegetables to avoid on their diet (25). Using a food knowledge score in addition to DMS, anthropometric and biochemical measurements could explain more why PEM is prevalent among all HDP.

In Turkey, Afsar et al. sought to determine the reliability of the Mini Nutritional Assessment (MNA) instrument in verifying malnutrition in HDP when compared to the original SGA. The MNA categories for assessing nutritional status were (1) no malnutrition, (2) moderate malnutrition, and (3) severe malnutrition which corresponded to A, B, C, of the SGA. The subjects were 137 HDP who had PEM with no signs of chronic inflammation. The nutritional status of the subjects was measured concurrently with both MNA and SGA. Ninety-two patients were in SGA-A, 40 were in SGA-B, and 5 were in SGA-C. While for the MNA, 47 patients were placed in MNA-1, 77 were placed in MNA-2, and 13 in MNA-3. There was a variance in the results obtained in both cases in that 52 patients who were without any evidence of malnutrition according to SGA were identified by the MNA as having moderate malnutrition. Seven patients, who were identified as having moderate malnutrition by the SGA, had good nutritional status according to the MNA. Eight other patients, who were identified by the SGA as being moderately malnourished, were defined by MNA as having severe malnutrition (26). Thus, this research suggests that MNA may not be as reliable as SGA in the detection of moderate malnutrition in HDP who are not in an 
inflammatory state, as it may underestimate it.

Three studies were conducted in Riyadh, the capital of Saudi Arabia to evaluate the nutritional status of HDP. In early 2006, researchers assessed 61 HDP from three hospitals in Riyadh to determine their nutritional status. Nutritional status was indicated by using a 3-day food record, anthropometric measure of BMI and biochemical measurements of albumin, hemoglobin and hematocrit. Over $95 \%$ of the 61 HDP had below-recommended energy intake levels, and over $80 \%$ of them were consuming less protein than recommended. Mean BMI was approximately $25 \mathrm{~kg} / \mathrm{m}^{2}$ for both men and women. The researchers concluded that $60 \%$ of HDP had significantly lower than normal serum albumin levels, classifying them as malnourished (2). In 2007, Alshatwi examined the nutritional parameters of 32 male HDP from Riyadh Central Hospital in Riyadh and compared them to 39 aged-matched healthy male subjects. The researcher collected 3-day food record and BMI from all subjects. Also, researchers collected albumin, total protein from both groups and collected creatinine and urea from HDP only. Analysis of food intake showed that the mean energy and protein intake was significantly higher in the healthy subjects than HDP $(\mathrm{p}<.001$ and $\mathrm{p}<.05$, respectively). Findings showed that the mean BMI was significantly lower in HDP $(\mathrm{p}<.001)$ compared to the healthy group. All healthy subjects had normal serum albumin levels ( $>4.0 \mathrm{~g} / \mathrm{dl})$ and only $18.7 \%$ of HDP had normal albumin levels for HDP ( $\geq 3.5 \mathrm{~g} / \mathrm{dL}$ ). Also, total protein was significantly lower in HDP $(\mathrm{p}<.001)$ and both urea and creatinine levels were significantly higher in HDP $(p<.001)$ compared to healthy subjects $(3)$. These studies documented the existence of malnutrition in Saudi HDP. However, both studies did not estimate the nutritional status according to SGA, therefore the accuracy of the results is questionable because 
neither study measured somatic protein (muscle mass).

During the period from September 2007 to September 2008 a cross-sectional study was conducted with 200 HDP in the Prince Salman Center for Kidney Diseases (PSCKD), Riyadh, Saudi Arabia to estimate the prevalence of malnutrition, obesity and to share solutions to these problems for the management of nutritional disorders in Saudi HDP. The original SGA was completed for these HDP. The BMI was calculated and each patient reported their dietary intake. Biochemical measurements of albumin, total protein, fasting lipid profile, creatinine, calcium, phosphorus, peripheral blood cell count for lymphocytes, fasting glucose, glycosylated hemoglobin, pre and post dialysis blood urea nitrogen were collected to evaluate visceral and somatic protein. The SGA categorized HDP into $68 \%$ well nourished, $24 \%$ mild to moderately malnourished, and $8 \%$ with severe malnutrition. The dietary intake of each patient was compared to the National Kidney Foundation Dialysis Outcome Quality Initiative guidelines for nutrition. Results indicated $89 \%$ of HDP had minimal or no change in their diet, whereas $9 \%$ HDP had mild to moderate decrease in their food consumption. The researchers observed that $4 \%$ of HDP were underweight, 49\% were average weight, $27.5 \%$ were overweight, $14 \%$ were obese, and $5.5 \%$ were morbidly obese. Severe malnutrition was significantly higher in males $(p=.04)(4)$. This study was the only Saudi study that nutritionally assessed HDP with the SGA and anthropometric and biochemical parameters. Therefore, their results could be considered more valid.

In conclusion, the percentage of patients who were assessed as having any degree of malnutrition in the Americas, Europe, and Western Pacific regions varied dramatically from as low as $9.2 \%$ to as high as $87.8 \%$ being mild or severely malnourished $(9,12-19)$. 
However, in the Eastern Mediterranean and South East Asia regions, most of the studies detected malnutrition in more than one-third of the patients $(2-4,20-26)$. The Eastern Mediterranean and South East Asia regions had higher percentage of PEM (over 90\%) when compared to the Americas, Europe, and Western Pacific regions $(\leq 87.8 \%)(2-4,9$, 12-26).

Since it is essential to apply different parameters to indicate PEM in HDP, all countries in the Americas, Europe, and Western Pacific regions used various methods such as SGA, anthropometric measurements, biochemical measurements, and diet recall (9, 12-19). However, not all countries in the Eastern Mediterranean and South East Asia regions used a combination of methods and that may have affected the accuracy of detecting PEM in HDP (2-4, 20-26). Generally, in order to accurately assess PEM in HDP, all studies in different regions agreed that more than one type of measurement is necessary $(2-4,9,12-26)$.

All three studies conducted in Saudi Arabia concluded that malnutrition was a common problem for HDP and that these patients were at a great risk of mortality and morbidity (2-4). Despite these studies' conclusions and the rising number of HDP in Saudi Arabia, PEM is still not assessed regularly in many parts of this country. Therefore, a study is warranted to assess PEM in other parts of Saudi Arabia. 


\section{METHODS}

A cross-sectional study was conducted to assess the nutritional status of HDP who had end stage renal disease at the Jeddah Kidney Center, The King Fahd General Hospital, Jeddah, Saudi Arabia. The Institutional Review Board of Florida International University along with The King Fahd General Hospital approved the study. To ensure the Arabic consent form contained the key elements of the English version, the consent form was back translated. The PI translated the consent form into Arabic then another person translated the Arabic consent into English without seeing the original consent. The original English version and the translated consent were compared for accuracy. The Arabic version of the consent form was determined to be accurate and appropriate in obtaining consent from the participants.

The principal investigator was trained on how to evaluate HDP with the 7-point SGA and use body fat calipers and a measuring tape to measure TSF and MAC under the direction of Ms. Linda McCann, RD, CSR of Satellite Healthcare, Inc. (Mountain View, CA). Ten HDP were evaluated to learn the consistent application of the SGA, TSF and MAC. Ms. Linda McCann is considered an expert in determining the nutritional status of HDP by using SGA and anthropometric measurements. She trained many practitioners in the last 20 years with SGA. Also, she has published numerous papers on the topic of SGA (27).

\section{Subjects}

A convenience sample of 315 patients was recruited for the study during May 2009. All those who participated met the following inclusion criteria: 1) male or female; 
2) age 18 years or older; 3 ) hemodialyzed for at least six months with continuing dialysis three times a week; 4) not hospitalized ; and 5) absence of enteral or parenteral feeding.

\section{Protocol}

Patients were asked to participate in the study when they came to the Jeddah Kidney Center for dialysis. The purpose of the study was explained to each patient and then the patient chose to accept or decline to participate. If a patient expressed interest in participating, (h)she was asked his/her age and the length of time on hemodialysis. Responses to those questions ascertained if the patient met the inclusion criteria. Those patients who did not meet the inclusion criteria were thanked for their time and not included in the study.

Data were collected in two phases: pre-dialysis and post-dialysis. During the pre-dialysis phase, the patient read and signed the consent form. However, if the patient was illiterate, the caregiver read the consent form to him/her and then the patient made a simplified mark or thumb print on the consent form (Appendix 1).

After obtaining consent, the patient was asked questions from the Personal, Diet, and Health Questionnaire (Appendix 2) (28). With the patient's permission, the patient's file was examined to acquire the necessary anthropometric and biochemical data such as height, pre-dialysis weight, and post-dialysis dry weight from the previous dialysis treatment, as well as serum albumin (Appendix 3). Lastly, a 24-hour dietary recall was obtained from the patient and recorded on a food data sheet (Baxter Healthcare Company, Deerfield, Illinois) (Appendix4).

The second phase of the data collection commenced after dialysis. The 7-point SGA was completed and the anthropometric measurements (post dialysis dry weight, 
TSF, and MAC) were taken (Appendix 5). The anthropometric measurements were obtained after dialysis in order to eliminate water retention from affecting the accuracy of the measurements.

\section{Assessment Instruments \& Measures}

Personal, Health, and Diet Questionnaire: A Personal, Diet, and Health questionnaire was developed to illicit general information about the patients. It consisted of 20 questions, ten of which were related to patient demographics, four regarding health and six pertaining to diet and fluid restriction non-adherence (Appendix 2). Demographic parameters incorporated sex, age, marital status, ownership of residence, residential location, nationality, education level, employment, income, and number of people living in the same household.

The questions pertaining to health status include the number of years the patient has lived with kidney disease, the number of years on hemodialysis, the medications s/he had been taking, and the presence or absence of co-morbid diseases.

Lastly, each patient was asked if $\mathrm{h} / \mathrm{she}$ had a dietitian or physician prescribe a diet and/or fluid guidelines. To assess diet and fluid compliance the validated Dialysis Diet and Fluid Non-adherence questionnaire was administered (28). The instrument includes four questions. The first question asks how many days the patient did not follow the diet guidelines in the past 14 days and the patient responds with a number. In the second question the digression is assessed on a five point Likert scale (0-no deviation, 1-mild deviation, 2-moderate deviation, 3severe deviation and 4-very severe deviation). Similar questions are posed to the patient regarding fluid guidelines.

Seven-Point Subjective Global Assessment: The 7-point SGA has been indicated as a 
reliable and valid tool for the nutritional assessment of $\operatorname{HDP}(5,7,8,15,29)$. The 7-point SGA includes two major categories: the history and physical examination (Appendix 5).

The history portion of the 7-point SGA is comprised of five sections: weight/weight change; dietary intake; gastrointestinal symptoms; functional capacity; and disease state/co-morbidities as related to nutritional status. For weight/weight change, the patient's weight loss from the preceding six months is recorded along with the current weight. All information regarding weight for the SGA was acquired from the patient's medical record. Other information required for the SGA was obtained from the interview with the patient.

To obtain the dietary intake of the patient, the patient was asked to recall all foods and beverages consumed during the previous 24 hours. Gastrointestinal symptoms such as, nausea, vomiting, and/or diarrhea were recorded from the patient's self report. The gastrointestinal symptoms are considered significant if most or all symptoms have persisted for at least two weeks. Short term or intermittent symptoms are not considered significant. To assess physical functional status, patients were asked to describe their physical capabilities. The functional capacity must be related to changes associated with nutritional status (e.g. anemia, low dietary intake), and changes in the previous six months. The final feature of the history portion is co-morbid diseases related to nutritional needs (e.g. hypertension, diabetes).

The second major category of the 7-point SGA is the physical examination. The physical examination includes an evaluation of the patient for fat and muscle wasting and edema. The area below the eye and around the tricep and bicep muscles was evaluated to determine subcutaneous fat loss. Muscle wasting was assessed by examining the 
temporalis muscle, prominence of the clavicles, the contour of the shoulders (rounded indicates well-nourished; squared indicates malnutrition), visibility of the scapula, interosseous muscle between the thumb and forefinger, and the gastrocnemius muscle. The area of the ankles was evaluated to determine edema. In HDP, it is critical that weight change and edema be assessed in tandem to determine if tissue wasting is masked by fluid retention.

Each section of the 7-point SGA was rated on a scale from one to seven. On the basis of subjective consideration of all the scores from each category, an overall number was assigned to each patient. A six or seven indicated very mild risk of malnutrition to well-nourished; a three, four, or five rating determined mild to moderate malnutrition; and one or two revealed severe malnutrition (5). From those ratings patients were then classified into one of three groups, $1=$ well-nourished, $2=$ moderate malnutrition, and $3=$ severe malnutrition.

Anthropometric Measurements: Anthropometric parameters are reliable and valid measurements that indicate nutritional status in HDP (5-7). Several anthropometric measurements were obtained. Pre-and post-dialysis weight, height, TSF, and MAC were measured, and from these, the interdialytic weight gain, BMI, and MAMC were calculated.

The BMI was calculated according to the patient's post-dialysis weight $(\mathrm{kg})$ divided by height $(\mathrm{cm})$ squared. Height was measured to the nearest $0.1 \mathrm{~cm}$. Dry weight was measured to the nearest $0.1 \mathrm{~kg}$ with a calibrated Seca medical scale (Hamburg, Germany). To determine interdialytic weight gain, the patient's weight at the beginning of the hemodialysis session on the day of the data collection was subtracted from the 
patient's weight after the previous hemodialysis session (5).

Mid-arm circumference was measured with a flexible non stretchable measure tape. The patient was asked to stand with his/her feet together, shoulders relaxed, and arms hanging freely at the sides. The non access (fistula free) arm was located to avoid the possibility of an inaccurate measurement due to fluid retention in the arm with the fistula. The midpoint on the posterior aspect of the upper arm was established between the acromial and olecranon and marked with a pencil. The measuring tape was placed around the upper arm at midpoint and pulled snugly enough to ensure contact with the arm. The measurement was recorded to the nearest centimeter. Three measurements of MAC were obtained and then the average was calculated.

Triceps skin-fold thickness was measured with a body fat caliper (Lange Skinfold Calipers, Power System, Tennessee, USA). At the midpoint where the skin was marked, a fold of skin with subcutaneous adipose tissue was grasped gently with the thumb and forefinger. With the jaws of the caliper perpendicular to the length of the fold, they were closed around the skin-fold. The skin-fold thickness was measured to the nearest $1 \mathrm{~mm}$. The measurement was repeated thrice and the average was calculated.

Mid-arm arm muscle circumference was calculated from the MAC and the TSF by the following formula: MAMC $(\mathrm{cm})=\operatorname{MAC}(\mathrm{cm})-[3.1415 \times \mathrm{TSF}(\mathrm{cm})](5)$.

Biochemical Measurements: Serum albumin was obtained to assess the nutritional status of these HDP, as several studies have demonstrated that albumin is a valid indicator of nutritional status in $\operatorname{HDP}(12,14,23)$. According to the NKF, serum albumin equal to or greater than $4 \mathrm{~g} / \mathrm{dL}$ is the outcome goal for HDP (5). The value of serum albumin was taken from all patients on May 2, 2009 prior to obtaining the 
values from the patient's medical record. Serum albumin is obtained from all patients in a monthly basis. All albumin values were categorized into either optimal ( $\geq 4 \mathrm{~g} / \mathrm{dL})$ or suboptimal $(<4 \mathrm{~g} / \mathrm{dL})$.

\section{Statistical Analysis}

All data were analyzed by the SPSS, version 17, Chicago, Illinois. Frequencies and percentages were determined for categorical variables and means and standard deviations were calculated for all continuous variables. Because frequency of severely malnourished was very small, it was combined with moderately malnourished to compare to well nourished. Cross tabulations with chi-square tests were used to determine unadjusted odds ratios between the 7-point SGA (well nourished, moderately to severely malnourished) and the categorical variables of gender, age $(<55$ and $\geq 55)$. T-tests were performed to compare the continuous variables [albumin, BMI, TSF, MAMC, IWG] by gender and age group. Spearman correlations were calculated to determine bivariate relationships between the three levels of the 7-point SGA and albumin, BMI, TSF, MAMC, IWG, and diet and fluid deviation.

Logistic regression was performed to estimate the magnitude of association between the degree of malnutrition (well nourished, severely to moderately malnourished) and the independent variables (albumin, BMI, TSF, MAMC, IWG, diet deviation, fluid deviation, gender, age, education, income, duration on hemodialysis, and number of people in a household). Odd ratios were tested to estimate the likelihood risk of these variables compared to SGA categories. The statistical significance for all tests was set at $\mathrm{p}=.05$. 


\section{RESULTS}

\section{Subject Demographics}

Of the 315 patients asked to participate, 270 participated in the study. Thirty patients did not complete the study and 15 others declined to participate. The sample consisted of 165 males and 105 females with the majority (79.6\%) being Saudi (Table 1). Of the 270 who participated, $187(69.3 \%)$ were younger than 55 years old, while the remaining $83(30.7 \%)$ were 55 years old and older (Table 1). Almost three-fourths of the patients were married (Table 1$)$. Nearly all the patients $(94.1 \%)$ resided in Jeddah and over half of the patients (51.9\%) rented their houses (Table 1). Almost half of the patients $(48.9 \%)$ lived with five or more people (Table 1). More than a third of the patients (34.1\%) were without education and only an eighth of the patients (12.6\%) graduated from high school (Table 1). The majority of the patients $(80.7 \%)$ were unemployed, and about half of the patients had incomes of less than 3000 Riyals (Table 1). More than half of the patients $(53.3 \%)$ had kidney disease and have been on hemodialysis for more than 5 years (Table 1). Most of the participants were prescribed at least seven common hemodialysis medications (folic acid, alfacalcidol, calcium carbonate, iron sucrose, acetaminophen, ranitidine, and furosemide). Most patients $(>80 \%)$ had a chronic disease in addition to ESRD (Table 1), such as hypertension (54.5\%), diabetes $(2.2 \%)$ or hypertension and diabetes combined (17.4\%) (Table 2).

\section{Diet and Fluid Prescription and Deviation}

A physician or a dietitian prescribed a diet to a majority of the patients $(85.6 \%)$ (Table 1$)$. Also, a majority of patients $(82.6 \%)$ received instructions for a fluid restriction from a physician or dietitian (Table 1$)$. Over half of the patients $(58.5 \%)$ deviated from 
their diet restrictions, however, less than half (48.1\%) deviated from their fluid restrictions (Table3).

\section{Prevalence of Malnutrition}

More than half of the patients $(54.1 \%)$ had some form of malnutrition according to their SGA score, either mildly to moderately malnourished or severely malnourished (Table 4). Only 45.9\% $(n=124)$ were well nourished (Table 4). Females were significantly more malnourished than males $(\mathrm{p}=.001)$ (Table 5). Females had significantly higher TSF than males $(\mathrm{p}=.01)$ (Table 7). Females had significantly lower IWG when compared to males $(\mathrm{p}=.003)$ (Table 7). Older patients $(\geq 55)$ were significantly more malnourished than younger patients $(<55)(\mathrm{p}=.001)$ (Table 6). Also, older patients $(\geq 55)$ had a significantly lower MAMC when compared to younger patients $(<55)(\mathrm{p}=.01)($ Table 8$)$.

Albumin, BMI, TSF, MAMC, IWG positively correlated with the 7-point SGA $(\mathrm{r}=.16, \mathrm{p}=.007 ; \mathrm{r}=.33, \mathrm{p}=<.001 ; \mathrm{r}=.38, \mathrm{p}=<.001 ; \mathrm{r}=.35, \mathrm{p}=<.001 ;$ and $\mathrm{r}=.20, \mathrm{p}$ $=.001$ respectively) (Table 9). However, diet and fluid deviation did not correlate to 7point SGA $(\mathrm{r}=.04, \mathrm{p}=.449 ; \mathrm{r}=.01, \mathrm{p}=.784$ respectively) (Table 9).

Odd ratios showed that for each decrease in one BMI unit the patient will be 3.5 times more likely to be malnourished $(\mathrm{p}=<.001)$ (Table 10). Also, for each decrease in one unit of TSF or MAMC, the patient will be 1.1 times more likely to be malnourished $(\mathrm{p}=.001$ for each) (Table 10). Males and younger patients $(<55)$ were .4 less likely to be malnourished than females and older patients $(\geq 55)(\mathrm{p}=.001$ for each) (Table 10). Also, patients without education were three times more likely to be malnourished than patients with elementary school or higher education $(\mathrm{p}=.001)($ Table 10$)$. 
Table 1: Demographic characteristics of hemodialysis patients at the Jeddah Kidney Center, Jeddah, Saudi Arabia $(\mathrm{n}=270)$

\begin{tabular}{|c|c|}
\hline Characteristic & Percent (n) \\
\hline \multicolumn{2}{|l|}{ Sex } \\
\hline Male & $61.1 \%(165)$ \\
\hline Female & $38.9 \%(105)$ \\
\hline \multicolumn{2}{|l|}{ Age } \\
\hline $18-24$ & $5.9 \%(16)$ \\
\hline $25-34$ & $13.3 \%(36)$ \\
\hline $35-44$ & $21.1 \%(57)$ \\
\hline $45-54$ & $28.9 \%(78)$ \\
\hline $55-64$ & $14.8 \%(40)$ \\
\hline 65 and over & $15.9 \%(43)$ \\
\hline \multicolumn{2}{|l|}{ Married } \\
\hline Yes & $73.0 \%$ (197) \\
\hline No & $27.0 \%(73)$ \\
\hline \multicolumn{2}{|l|}{ Reside } \\
\hline City & $94.1 \%(254)$ \\
\hline Village & $5.9 \%(16)$ \\
\hline \multicolumn{2}{|l|}{ Type of Residence } \\
\hline Owned & $44.8 \%(121)$ \\
\hline Rent & $51.9 \%(140)$ \\
\hline \multicolumn{2}{|l|}{ Nationality } \\
\hline Saudi & $79.6 \%(215)$ \\
\hline Non-Saudi & $20.4 \%(55)$ \\
\hline \multicolumn{2}{|l|}{ Education } \\
\hline None & $34.1 \%(92)$ \\
\hline Elementary School & $23.7 \%(64)$ \\
\hline Middle School & $14.8 \%(40)$ \\
\hline High School & $12.6 \%(34)$ \\
\hline Diploma & $4.4 \%(12)$ \\
\hline Bachelor's Degree & $9.3 \%(25)$ \\
\hline Master's Degree & $1.1 \%(3)$ \\
\hline \multicolumn{2}{|l|}{ Employed } \\
\hline Yes & $19.3 \%(52)$ \\
\hline No & $80.7 \%(218)$ \\
\hline Student & $.7 \%(2)$ \\
\hline Retired & $22.2 \%(60)$ \\
\hline Housewife & $35.6 \%(96)$ \\
\hline Unemployed & $22.2 \%(60)$ \\
\hline
\end{tabular}


Table 1: Demographic characteristics of hemodialysis patients at the Jeddah Kidney Center, Jeddah, Saudi Arabia ( $\mathrm{n}=270)$ (cont.)

\begin{tabular}{lc}
\hline Characteristic & Percent (n) \\
\hline Income & $49.6 \%(134)$ \\
Less than 3000 Riyals & $34.1 \%(92)$ \\
3000 Riyals but less than 6000 Riyals & $7.0 \%$ \\
6000 Riyals but less than 10000 Riyals & $(19)$ \\
& $9.3 \%(25)$ \\
More than 10000 Riyals & \\
Number of People in Household & $15.2 \%(41)$ \\
Less than 3 people & $35.9 \%(97)$ \\
3 to 5 people & $48.9 \%(132)$ \\
More than 5 people & \\
Years with Kidney Disease & $6.7 \%(18)$ \\
6 months but less than a year & $41.1 \%(111)$ \\
A year but less than 5 years & $21.9 \%(59)$ \\
5 years but less than 10 years & $30.4 \%(82)$ \\
10 years or more & \\
Duration of Hemodialysis & $6.7 \%(18)$ \\
Less than a year & $41.1 \%(111)$ \\
A year but less than 5 years & $22.2 \%(60)$ \\
5 years but less than 10 years & $18.5 \%(50)$ \\
10 years but less than 15 years & $9.3 \%(25)$ \\
15 years but less than 20 years & $2.2 \%(6)$ \\
Presence of Co-morbidity & \\
Yes & $80.4 \%(217)$ \\
No & $19.6 \%(53)$ \\
Yes & \\
No & $85.6 \%(231)$ \\
Yes & $14.4 \%(39)$ \\
No & \\
\hline & $82.6 \%(223)$ \\
Physian/Dietitian Prescribed Diet & $17.4 \%(47)$ \\
\hline
\end{tabular}


Table 2: Presence of co-morbidities in hemodialysis patients at the Jeddah Kidney Center, Jeddah, Saudi Arabia $(n=217)$

\begin{tabular}{lc}
\hline Co-morbidity & Percent (n) \\
\hline Hypertension & $54.5 \%(147)$ \\
Hypertension/Diabetes & $17.4 \%(47)$ \\
Diabetes & $2.20 \%(6)$ \\
Other & $6.30 \%(17)$ \\
\hline
\end{tabular}

Table 3: Self-reported deviation from diet prescription and fluid restriction of hemodialysis patients at the Jeddah Kidney Center, Jeddah, Saudi Arabia $(n=270)$

\begin{tabular}{ll}
\hline Question/Response & Percent (n) \\
\hline Deviation from Diet Prescription & \\
No-Deviation & $41.5 \%(112)$ \\
Mild-Moderate Deviation & $28.5 \%(77)$ \\
Severe-Very Severe Deviation & $30.0 \%(81)$ \\
Deviation from Fluid Restriction & \\
No-Deviation & $51.9 \%(140)$ \\
Mild-Moderate Deviation & $18.1 \%(49)$ \\
Severe-Very Severe Deviation & $30.0 \%(81)$ \\
\hline
\end{tabular}

Table 4: Percent of hemodialysis patients who are either nourished or malnourished according to the Subjective Global Assessment at the Jeddah Kidney Center in Jeddah, Saudi Arabia $(\mathrm{n}=270)$

\begin{tabular}{ccc}
\hline $\begin{array}{c}\text { Well Nourished } \\
\% \text { (n) }\end{array}$ & $\begin{array}{c}\text { Mildly to } \\
\text { Moderately Malnourished } \\
\%(\mathbf{n})\end{array}$ & $\begin{array}{c}\text { Severely } \\
\text { Malnourished } \\
\% \text { (n) }\end{array}$ \\
\hline $45.9 \%(124)$ & $47.8 \%(129)$ & $6.3 \%(17)$ \\
\hline
\end{tabular}


Table 5: Nutritional status difference between genders according to the 7-point Subjective Global Assessment at the Jeddah Kidney Center, Jeddah, Saudi Arabia $(\mathrm{n}=270)$

\begin{tabular}{|c|c|c|c|}
\hline Gender & $\begin{array}{c}\text { Well Nourished } \\
(\%)\end{array}$ & $\begin{array}{l}\text { Moderately to } \\
\text { Severely } \\
\text { Malnourished } \\
(\%)\end{array}$ & $P$ Value \\
\hline $\begin{array}{l}\text { Male } \\
\text { Female }\end{array}$ & $\begin{array}{l}53.9 \\
33.3\end{array}$ & $\begin{array}{l}46.1 \\
66.7\end{array}$ & .001 \\
\hline
\end{tabular}

$p<.05$

Table 6: Nutritional status difference between younger $(<55$ years old) and older $(\geq 55$ years old) hemodialysis patients according to the 7-point Subjective Global Assessment at the Jeddah Kidney Center, Jeddah, Saudi Arabia $(n=270)$

\begin{tabular}{|c|c|c|c|}
\hline Age & $\begin{array}{c}\text { Well Nourished } \\
(\%)\end{array}$ & $\begin{array}{l}\text { Moderately to } \\
\text { Severely } \\
\text { Malnourished } \\
(\%) \\
\end{array}$ & $P$ Value \\
\hline$<55$ years & 57.8 & 42.2 & \multirow{2}{*}{.001} \\
\hline$\geq 55$ years & 37.8 & 62.2 & \\
\hline
\end{tabular}

$p<.05$

Table 7: Comparison of albumin, body mass index, tricep skin-fold, mid-arm muscle circumference, and interdialytic weight gain between male and female hemodialysis patients at the Jeddah Kidney Center, Jeddah, Saudi Arabia $(n=270)$

\begin{tabular}{|c|c|c|c|}
\hline \multirow[b]{2}{*}{ Nutritional Assessment Parameters } & \multicolumn{2}{|c|}{ Sex } & \multirow[b]{2}{*}{$P$ Value } \\
\hline & $\begin{array}{c}\text { Male } \\
(n=165)\end{array}$ & $\begin{array}{l}\text { Female } \\
(n=105)\end{array}$ & \\
\hline Albumin (g/dL) & $3.53 \pm .52^{1}$ & $3.44 \pm .42$ & .304 \\
\hline $\mathrm{BMI}^{\mathrm{a}}\left(\mathrm{kg} / \mathrm{m}^{2}\right)$ & $23.3 \pm 5.9$ & $21.9 \pm 6.2$ & .268 \\
\hline $\mathrm{TSF}^{\mathrm{b}}(\mathrm{mm})$ & $27.4 \pm 5.2$ & $28.2 \pm 6.7$ & .012 \\
\hline $\operatorname{MAMC}^{\mathrm{c}}(\mathrm{cm})$ & $23.4 \pm 4.0$ & $22.3 \pm 4.9$ & .288 \\
\hline $\mathrm{IWG}^{\mathrm{d}}(\mathrm{kg})$ & $2.20 \pm 1.4$ & $1.94 \pm .86$ & .003 \\
\hline \multicolumn{4}{|l|}{$p<.05$} \\
\hline $\begin{array}{l}{ }^{a} \text { BMI }=\text { Body Mass Index } \\
{ }^{\mathrm{b}} \mathrm{TSF}=\text { Triceps Skin Fold } \\
{ }^{\mathrm{c}} \mathrm{MAMC}=\text { Mid Arm Muscle Circumference } \\
{ }^{\mathrm{d}} \mathrm{IWG}=\text { Interdialytic Weight Gain } \\
{ }^{1} \text { Mean } \pm \text { SD }\end{array}$ & & & \\
\hline
\end{tabular}


Table 8: Comparison of albumin, body mass index, tricep skin-fold, mid-arm muscle circumference, and interdialytic weight gain between hemodialysis patients aged $<55$ years old and $\geq 55$ years old at Jeddah Kidney Center, Jeddah, Saudi Arabi $(\mathrm{n}=270)$

\begin{tabular}{|c|c|c|c|}
\hline \multirow[b]{2}{*}{ Nutritional Assessment Parameters } & \multicolumn{2}{|c|}{ Age } & \multirow[b]{2}{*}{$P$ Value } \\
\hline & $\begin{array}{c}<55 \\
(n=187)\end{array}$ & $\begin{array}{c}\geq 55 \\
(n=83)\end{array}$ & \\
\hline Albumin $(\mathrm{g} / \mathrm{dL})$ & $3.52 \pm .53^{1}$ & $3.48 \pm .49$ & .814 \\
\hline $\mathrm{BMI}^{\mathrm{a}}\left(\mathrm{kg} / \mathrm{m}^{2}\right)$ & $21.8 \pm 6.1$ & $23.5 \pm 6.0$ & .557 \\
\hline $\mathrm{TSF}^{\mathrm{b}}(\mathrm{mm})$ & $27.5 \pm 6.5$ & $27.9 \pm 5.4$ & .155 \\
\hline $\operatorname{MAMC}^{\mathrm{c}}(\mathrm{cm})$ & $23.1 \pm 5.4$ & $22.9 \pm 3.6$ & .013 \\
\hline $\mathrm{IWG}^{\mathrm{d}}(\mathrm{kg})$ & $2.17 \pm 1.2$ & $1.88 \pm 1.3$ & .909 \\
\hline
\end{tabular}

$p<.05$

${ }^{\mathrm{a}} \mathrm{BMI}=$ Body Mass Index

${ }^{\mathrm{b}} \mathrm{TSF}=$ Triceps Skin Fold

${ }^{\mathrm{c}} \mathrm{MAMC}=$ Mid Arm Muscle Circumference

${ }^{\mathrm{d}} \mathrm{IWG}=$ Interdialytic Weight Gain

${ }^{1}$ Mean \pm SD

Table 9: Albumin, body mass index, tricep skinfold, mid-arm muscle circumference, interdialytic weight gain, diet prescription deviation, or fluid restriction deviation correlated with the Subjective Global Assessment (well nourished, moderately malnourished, severely malnourished) for hemodialysis patients at Jeddah Kidney Center, Jeddah, Saudi Arabia $(\mathrm{n}=270)$

\begin{tabular}{lcc}
\hline & \multicolumn{2}{c}{ 7- point Subjective Global Assessment } \\
\cline { 2 - 3 } Nutritional Assessment Parameters & Spearman's rho & P Value \\
& & \\
Albumin $(\mathrm{g} / \mathrm{dL})$ & .16 & .007 \\
$\mathrm{BMI}^{\mathrm{a}}\left(\mathrm{kg} / \mathrm{m}^{2}\right)$ & .33 & $<.001$ \\
$\mathrm{TSF}^{\mathrm{b}}(\mathrm{mm})$ & .38 & $<.001$ \\
$\mathrm{MAMC}^{\mathrm{c}}(\mathrm{cm})$ & .35 & .001 \\
IWG $^{\mathrm{d}}(\mathrm{kg})$ & .20 & .001 \\
Diet Prescription Deviation & .04 & .449 \\
Fluid Restriction Deviation & .01 & .784 \\
\hline$p<.05$ & & \\
${ }^{\mathrm{a}} \mathrm{BMI}=$ Body Mass Index & & \\
${ }^{\mathrm{b}} \mathrm{TSF}=$ Triceps Skin Fold & & \\
${ }^{\mathrm{c}} \mathrm{MAMC}=$ Mid Arm Muscle Circumference & & \\
${ }^{\mathrm{d}} \mathrm{IWG}=$ Interdialytic Weight Gain &
\end{tabular}


Table 10: Odds ratios of malnutrition by albumin, body mass index, tricep skin-fold, mid-arm muscle circumference, interdialytic weight gain, diet deviation, fluid deviation, gender, age, education, income, hemodialysis length or number of people in a household in hemodialysis patients at Jeddah Kidney Center, Jeddah, Saudi Arabia (n=270)

7- point Subjective Global Assessment

\begin{tabular}{rcc}
\hline OR & 95 \% CI & $P$ Value \\
& & \\
.88 & $(0.50,1.55)$ & .658 \\
2.90 & $(1.38,6.30)$ & .005 \\
3.56 & $(2.08,6.13)$ & $<.001$ \\
1.12 & $(1.07,1.19)$ & .001 \\
1.15 & $(1.07,1.27)$ & .001 \\
1.42 & $(1.12,1.80)$ & .003 \\
1.07 & $(.804,1.43)$ & .629 \\
.96 & $(.729,1.27)$ & .785 \\
.43 & $(0.26,0.71)$ & .001 \\
.45 & $(0.27,0.73)$ & .001 \\
3.10 & $(1.81,5.34)$ & .001 \\
1.11 & $(0.86,1.48)$ & .417 \\
1.11 & $(0.68,1.81)$ & .668 \\
1.12 & $(0.81,1.58)$ & .484 \\
\hline
\end{tabular}

$\operatorname{Albumin}(<4 \mathrm{~g} / \mathrm{dL}, \geq 4 \mathrm{~g} / \mathrm{dL})$

BMI (normal weight $<29.9 \mathrm{~kg} / \mathrm{m}^{2}$, overweight $>30 \mathrm{~kg} / \mathrm{m}^{2}$ ) (underweight $<20 \mathrm{~kg} / \mathrm{m}^{2}$, normal weight $\geq 20 \mathrm{~kg} / \mathrm{m}^{2}$ )

$\mathrm{TSF}^{\mathrm{b}}(\mathrm{mm})$

$\operatorname{MAMC}^{\mathrm{c}}(\mathrm{cm})$

$\mathrm{IWG}^{\mathrm{d}}(\mathrm{kg})$

Diet Deviation

Fluid Deviation

Gender (male, female)

Age $(<55, \geq 55)$

Education (none, $\geq$ elementary school)

Income

Duration on Hemodialysis ( $<5$ years, $\geq 5$ years)

$1.12 \quad(0.81,1.58)$

.484

$p<.05$

${ }^{\mathrm{a}} \mathrm{BMI}=$ Body Mass Index

${ }^{\mathrm{b}} \mathrm{TSF}=$ Triceps Skin Fold

${ }^{c}$ MAMC $=$ Mid Arm Muscle Circumference

${ }^{\mathrm{d}} \mathrm{IWG}=$ Interdialytic Weight Gain 


\section{DISCUSSION}

In Saudi Arabia, the prevalence of PEM in HDP has been documented only in the capital city of Riyadh. This study was the first to detect PEM among HDP in Jeddah, Saudi Arabia with an inexpensive nutritional assessment protocol consisting of the 7-point SGA, albumin, and anthropometric measurements (BMI, TSF, MAMC, and IWG). Notably, the majority of patients at the Jeddah Kidney Center were moderately to severely malnourished.

In the Jeddah Kidney Center, patients were Saudi, young $(<55)$, poor $(<3000$ Riyals/ month) with no employment and little or no education. As the population of Saudi Arabia is 55 years old or younger according to the World Health Organization, the majority of these HDP reflect the age of the Saudi Arabian population (30).

Although more young Saudi Arabians were HDP, a higher percentage of older HDP (55 years or older) were malnourished. Several studies demonstrated that malnutrition correlated with lower MAMC in $\operatorname{HDP}(9,15,17,18,21-23)$. The correlation between lower MAMC in older HDP and malnutrition could be the factor that led to higher percentage of older HDP being malnourished. The higher percentage of older HDP being malnourished was consistent with Basaleem et al. study, as he found that older patients ( $\geq 50$ years) were more malnourished than younger patients ( $<$ 50 years) (25).

The higher percentage of malnourished females is different from the results of studies completed in Jordan and Saudi Arabia. In the Jordanian study, the researchers indicated that $75 \%$ of males were moderately to severely malnourished compared to $50 \%$ of females (23). The Saudi Arabian study found that malnutrition was higher in 
men (4).

\section{Diet and Fluid Adherence}

More patients seem to have deviated from their diet restrictions than from their fluid restrictions. Generally, the majority of patients did not adhere to their diet and fluid restrictions. It has been reported that $28-78 \%$ of HDP fail to adhere to prescribed diet and limiting fluid intake (28,32-34). The non-adherence in the previous studies may be related to several factors such as a rigid and complex diet that affected patient's food preferences and altered lifestyle, patient's perception of the usefulness of therapeutic diet was out weighed by the traditional beliefs, and patient did not ask questions about the diet or fluid restrictions either because he/she was embarrassed or did not have enough knowledge to know what to ask $(28,32-34)$. In addition to diet and fluid non-adherence factors in the previous studies that could relate to this study, diet and fluid non-adherence in this study may be due to the low educational level of the patients as they may not have understood the dietary and fluid restrictions and the significance of those restrictions. As these patients were poor and lived with more than three family members, their ability to cook and follow a restricted diet may have placed a burden on the patient's family who may not recognize the significance of following a special diet. Also, since information about the diet and fluid restrictions is communicated verbally without written instructions the patients may have forgotten the details of the diet and fluid prescription contributing to lack of adherence. The absence of a dietitian at this center may be a factor in the high number of patients not adhering to their diet and fluid restrictions, as consistent and frequent nutrition education and counseling is not provided to these patients. 


\section{Prevalence of Malnutrition}

More than half of the participants at the Jeddah Kidney Center were moderately to severely malnourished. The percentage of HDP in Jeddah found to be malnourished was different from the percentage of patients in the studies conducted in Riyadh. Two of the Riyadh studies found $60 \%$, and $81.3 \%$ of patients were malnourished, whereas this study detected 54\% malnutrition $(2,3)$. The large percentage of malnutrition in the Riyadh studies could be as a result of classifying patients as malnourished with only one parameter, serum albumin $(2,3)$. Serum albumin alone is not a reliable parameter to detect malnutrition as it could be affected by other factors such as inflammation, infection, hydration status, and acute or chronic stress (35-37). Also, NKF does not support the use of one single measure as it is not a comprehensive approach of indicating PEM. Single assessment parameter does not identify different aspects of PEM that include: energy and protein intake, visceral and somatic protein stratus and muscle and fat mass. Dietary interview and diaries provide quantitative information concerning intake of protein, energy and other nutrients. Albumin and prealbumin levels may be used to indicate visceral protein status in HDP. Evaluation of somatic protein can be performed by applying MAMC to measure the muscle mass. Also, creatinine serves as a useful measure in indicating skeletal muscle mass. Body Mass Index and TSF are generally assessed to indicate body fat mass (5). The most recent Riyadh study had a smaller percentage of malnutrition, only $32 \%$ of patients were malnourished (4). This smaller percentage in the PSCKD could be related to the presence of dietitians who provide continuous nutrition education and counseling to HDP. Also, the presence of an interdisciplinary team that includes a physician, nurse, 
dietitian, and social worker, considers different aspects that affect patient's health status (4).

An Indian study had a similar percentage of malnutrition as this study; Tapiawala et al. found $58 \%$ of HDP were malnourished (22). However, the percentage of malnutrition was higher in Yemen and Jordan (24-25). In contrast, studies completed in Pakistan, Iran and Turkey had smaller percentage (less than 50\%) of the patients malnourished (20,21, 26). Variation in the prevalence of malnutrition among HDP in eastern countries may be attributed to the different methods employed to assess nutritional status. As some countries applied a single method, the prevalence of malnutrition could vary widely since one method does not accurately estimate PEM. In contrast, some countries applied a combination of methods that could identify malnutrition with greater sensitivity therefore the percentage of malnourished patients may be accurate. Socioeconomic factors could also contribute to a higher percentage of malnutrition. A number of countries have older or uneducated populations and as a result the prevalence of malnutrition could be higher since old age and education may influence the nutritional status of HDP (25). Additionally, the prevalence of co-morbid diseases among HDP may vary among countries and HDP with co-morbid diseases tend to be malnourished (38).

\section{Correlation between Malnutrition and Nutritional Assessment Parameters}

Body mass index, TSF, and MAMC correlated with the nutritional status of HDP. These anthropometric measurements decreased as the patients became malnourished. Studies in Italy, the Netherlands, Sweden, Brazil, Iran and India supported these findings $(9,15,17,18,21,22)$. Also, the Jordanian study concluded that TSF and MAMC were 
significantly reduced as malnutrition became severe (23). However, the Australian study did not detect any correlation between TSF, MAMC and HDP nutritional status (14). Additionally, as the IWG increased the severity of the malnutrition increased. This is consistent with the study results of Yang et al. They suggested that the greater the IWG the poorer the nutritional status of HDP (39).

As in this study, several studies found that HDP with low albumin levels were malnourished $(9,14,15,17,18,21,22)$. However, Tapiawala et al. concluded that albumin levels did not correlate with malnutrition on 81 Indian HDP (22). Serum albumin may be influenced by non-nutritional factors and may fall acutely with infection, inflammation, hydration status, and acute or chronic stress (35-37).

Anthropometric measurements and albumin correlated significantly with the 7-point SGA confirming that are predictors of the nutritional status of HDP. Also, this verifies the importance of employing SGA in conjunction with other nutritional assessment parameters to get more accurate results. In summary, these methods are quick and reliable nutrition assessment tools that enable malnourished hemodialysis patients to be identified and triaged for appropriate nutrition intervention.

\section{Relative Odds of Malnutrition}

Anthropometrics, age, gender and education were significantly associated with the risk of malnutrition. Hemodialysis patients who were female ( $\mathrm{OR}=.43, \mathrm{p}=.001)$, older $(\mathrm{OR}=.45, \mathrm{p}=.001)$ with no education $(\mathrm{OR}=3.10, \mathrm{p}=.001)$, underweight $(\mathrm{OR}=3.56$, $\mathrm{p}<.001)$, small TSF $(\mathrm{OR}=1.12, \mathrm{p}=.001)$, small MAMC $(\mathrm{OR}=1.15, \mathrm{p}=.001)$, or high IWG $(\mathrm{OR}=1.42, \mathrm{p}=.003)$ were more likely to be malnourished. Gurreebun et al. considered HDP who had a BMI less than 18.5 to more likely be malnourished when compared to 
HDP with a higher BMI (12). Basaleem et al. suggested that the risk of malnutrition was higher among HDP with more than $2 \mathrm{~kg}$ of IWG than HDP with less than $2 \mathrm{~kg}$ of IWG (25). Additionally, Basaleem et al. found that older age ( $\geq 50$ years) patients and patients with no or little education were significantly associated with the risk of moderate to severe malnutrition (25). All these risk factors need to be considered collectively when assessing the nutritional status of these HDP. Dietitians should provide more attention to HDP who are 55 years or older, uneducated and with low BMI, TSF, and MAMC.

Study Limitation: The study was a cross sectional study which was implemented in patients from one kidney center in Saudi Arabia. This limited the number of patients and socioeconomic diversity of the HDP. This study only describes the HDP of Jeddah Kidney Center and can not be generalized to other centers in Saudi Arabia.

One biochemical measurement, albumin, was evaluated to detect the nutritional status. Assessing more biochemical parameters would have given a more comprehensive indication of PEM.

Recommendations: Permanent dietitians need to be hired for the Jeddah Kidney Center in Jeddah, Saudi Arabia and then trained to accurately assess the nutritional status of HDP. The dietitians need to implement this inexpensive nutritional assessment protocol that consists of the 7-point SGA, BMI, TSF, MAMC, IWG and albumin to detect malnutrition in HDP. Dietitians need to provide nutrition counseling and education to increase adherence to diet and fluid prescriptions.

The study population should be expanded to include HDP from more areas of Saudi Arabia to obtain a more comprehensive understanding of the nutritional status of HDP in this country. Additionally, studies that compare the prevalence of PEM in HDP 
in public versus private hospitals need to be completed to achieve a more comprehensive understanding of the affect of socioeconomic status on PEM. Lastly, evaluating the prevalence of PEM in HDP pre and post nutrition education will assist in verifying the importance of implementing nutritional management in HDP.

\section{CONCLUSION}

In conclusion, the prevalence of malnutrition is high in HDP living in Jeddah, Saudi Arabia. A higher percentage of females, older HDP with little or no education and HDP with lower BMI, TSF and MAMC were malnourished. Also, the nutritional assessment parameters used in this study were reliable, inexpensive, and easy to perform. The SGA was correlated with albumin, BMI, TSF, MAMC, and IWG. Additionally, anthropometrics, age, gender and education were significantly associated with the risk of malnutrition. Finally, the nutritional status of HDP needs more attention and regular periodic nutrition assessment needs to be implemented at least once every 6 months in addition to monthly albumin monitoring according to NKF nutritional guidelines (40). 


\section{REFERENCES}

1. Souqiyyeh M, Al-Attar M, Zakaria H, Shaheen F. Dialysis Centers in the Kingdom of Saudi Arabia. Saudi Journal of Kidney Disease and Transplantation. 2001; 12(3):293-304.

2. Alshatwi AA, Alshmary A, AL-Khalifa A. Nutritional assessment of hemodialysis patients. Journal of Medical Science. 2007;7(2):294-298.

3. Alshatwi AA. A comparative study of nutritional parameters in hemodialysis patients. Bulletin of Faculty of Agriculture, Cairo University. 2007;58: 105-111.

4. Alsaran K, Elsayed S, Molhem A, Aldrees A, Alzara H. Nutritional assessment of patients in a large dialysis Saudi center. Saudi Medical Journal. 2009;30(8):179-184.

5. The National Kidney Foundation Kidney Disease Outcome Quality Initiative (NKF KDOQI). American Journal of Kidney Disease. 2000;35(6).

6. Saxena, Sharma. An update on methods for assessment of nutritional status in maintenance dialysis patients. Indian Journal of Nephrology 2004;14:61-66.

7. Steiber A, Kalantar K, Secker D, McCarthy M, Sehgal A, McCann L. Subjective Global Assessment in Chronic Kidney Disease: A Review. Journal of Renal Nutrition 2004;14(4):191-200.

8. Campbell K, Ash S, Bauer J, Davies P. Critical review of nutrition assessment tools to measure malnutrition in chronic kidney disease. Nutrition \& Dietetics.2007; 64:23-303.

9. Enia, G, Sicuso, C, Alati, G, Zoccali, C. Subjective global assessment of nutrition in dialysis patients. Nephrology Dialysis Transplantations. 1993;8:1094-1098. 
10. Detsky AS, McLaughlin JR, Baker JP, Johnston N, Whittakers S, Mendelson RA, Jeejeebhoy KN. What is subjective global assessment of nutritional status? Journal of parenter \& Enteral Nutrition. 1987;11:8-13.

11. Churchill D, Thorpe K, Nolph K, Keshaviah P, Oreopoulos D, Page D. Increased peritoneal membrane transport is associated with decreased patient and technique survival for continuous peritoneal dialysis patients. American Society of Nephrology.1998;9:1285-1292.

12. Gurreebun F, Hartley GH, Brown AL, Ward MC, Goodship THJ. Nutritional screening in patients on hemodialysis: is subjective global assessment an appropriate tool? Journal of Renal Nutrition.2007;17(2):114-117.

13. Pifer TB, McCullough KP, Port FK, Goodkin DA, Maroni BJ, Held PJ, Young EW. Mortality risk in hemodialysis patients and chances in nutritional indicators: DOPPS. Kidney International.2002;62:2238-2245.

14. Desbrow B, Bauer J, Blum C, Kandasamy A, McDonald A, Montgomery K. Assessment of nutritional status in hemodialysis patients using patient-generated subjective global assessment. Journal of Renal Nutrition. 2005; 15(2):211-216.

15. Visser R, Dekkern FW, Boeschoten EW, Stevens P, Krediet RT. Reliability of the 7-point global assessment scale in assessing nutritional status of dialysis patients. Conference on Peritoneal Dialysis.1999;15:222-225.

16. Segall L, Mardare NG,Sorin Ungureanu S, Busuioc1 M, Nistor I, Enache1 R, Simona M, Covic A. Nutritional status evaluation and survival in haemodialysis patients in one centre from Romania. Nephrology Dialysis Transplantation. 2009; $24: 2536-2540$.

17. Quereshi AR, Alvestrand A, Danielsson A, Divino-Filho JC, Gutierrez A, Lindholm B, and Bergstrom J. Factors predicting malnutrition in hemodialysis patients: a cross-sectional study. Kidney International. 1998;53:773-782.

18. Morais AAC, Silva MAT, Faintuch J, Vidigal EJ, Costa RA, Lyrio DC, Trindade 
CR, Pitanga KK. Correlation of nutritional status and food intake in hemodialysis patients. Clinics. 2005;60(3):185-192.

19. Stojanovic M, Stojanovic D, Stefanovic V. The Impact of Malnutrition on Mortality in Patients on Maintenance Hemodialysis in Serbia. Artificial Organs. 2008;32(5):398-405.

20. Anees M, Ahmed AM, Rizwan SM. Evaluation status of patients on hemodialysis. Journal of College of Physicians and Surgeons Pakistan. 2004;14(11): 665-669.

21. Afshar R, Sanavi S, Izadi-Khah A. Assessment of nutritional status in patients undergoing maintenance hemodialysis: a single-center study from Iran. Saudi Journal of Kidney Diseases and Transplantation. 2007;18(3):397-404.

22. Tapiawala S, Vora H, Patel Z, Badve S, Shah B. Subjective global assessment of nutritional status of patients with chronic renal insufficiency and end stage renal disease on dialysis. Journal of the Association of The Physician of India. 2006;54:923-926.

23. Tayyem RF, Mrayyan MT. Malnutrition, anthropometric and biochemical abnormalities in end-stage renal disease patients. Saudi Medical Journal 2007; 28(10):1575-158.

24. Tayyem RF, Mrayyan MT, Heath DD, Bawadi HA. Assessment of nutritional status among ESRD patients in Jordanian hospitals. Journal of Renal Nutrition. 2008;18(3):281-287.

25. Basaleem HO, Alwan SM, Shmed AA, Al-Sakkaf KA. Assessment of the nutritional status of end-stage renal disease patients on maintenance hemodialysis. Saudi Journal of Kidney Diseases and Transplantation 2004; 15(4):455-462.

26. Afsar B, Sezer S, Arat Z, Tutal E, Ozdemir FN, Haberal M. Reliability of mini nutritional assessment in hemodialysis compared with subjective global assessment. Journal of Renal Nutrition. 2006;16(3):277-282.

27. Net Nutrition. Net Nutrition A-Z Scientific Advisory Board. Available at: 
https://secure.kidneytools.com/netnutrition/advisoryBoard.asp. Accessed April 21, 2010.

28. Vlaminck H, Maes B, Jacobs A, Reyntjens S, Evers G. The dialysis diet and fluid non-adherence questionnaire: validity testing of a self-report instrument for clinical practice. Journal of Clinical Nursing 2001;10:707-715

29. Steiber A, Leon JB, Secker D, McCarthy M, McCann L, Serra M, Sehgal AR, Kalantar-Zadeh K. Multicenter study of the validity and reliability of subjective global assessment in hemodialysis population. Journal of Renal Nutrition. 2007;17(5):336-342.

30. World Health Organization. Country Cooperation Strategy of WHO and Saudi Arabia 2006-2011. Available at: http://www.who.int/countryfocus/cooperation_strategy/ccs_sau_en.pdf.Accessed February 24, 2010.

31. Chertow GM, Johansen KL, Lew N, Lazarus JM, Lowrie EG. Vintage, nutritional status, and survival in hemodialysis patients. Kidney International. 2000;57:1176-1181.

32. Zrinyi M, Juhasz M, Balla J, Katona E, Ben TM, Kakuk G, Pall D. Dietary self-efficacy: determinant of compliance behaviors and biochemical outcomes in heamodialysis patients. Nephrology Dialysis Transplantation. 2003;18:1869-1873.

33. Lee S, Molassiotis A, Dietary and fluid compliance in Chinese hemodialysis patients. International Journal of Nursing Studies. 2002;39:695-704.

34. Durose CL, Holdsworth M, Watson V, Przygrodzka F. Knowledge of dietary restrictions and the medical consequences of noncompliance by patients on hemodilaysis are not predictive of dietary compliance. Journal of The American Dietetic Association. 2004;104:35-41.

35. Kaysen, Levin. Why measure Serum Albumin Levels? Journal of Renal Nutrition. 2002;12(3):148-150. 
36. Jones C, Akbani H, Croft D, Worth D. The relationship between serum albumin and hydration status in hemodialysis patients. Journal of Renal Nutrition. 2002;12(4):209-212.

37. Santos NS, Draibe SA, Kamimura MA, Canziani ME, Cendoroglo M, Junior $\mathrm{AG}$, Cuppari L. Is serum albumin a marker of nutritional status in hemodialysis patients without evidence of inflammation? Artificial Organs. 2003;27(8):681-686.

38. Prakash J, Sen D. Nutrition in dialysis patients. Journal of Association of Physicians of India.2000; 48.

39. Yang S, Chiang C, Hsu S, Hung K. Relationship between interdialytic weight gain and nutritional markers in younger and older hemodialysis patients. Journal of Renal Nutrition. 2008;18(2):210-222.

40. Kopple JD. National kidney foundation K/DOQI clinical practice guidelines for nutrition in chronic renal failure. American Journal of Kidney Diseases. 2001;37(1):66-70. 
APPENDICES 


\section{APPENDIX I \\ CONSENT FORM}




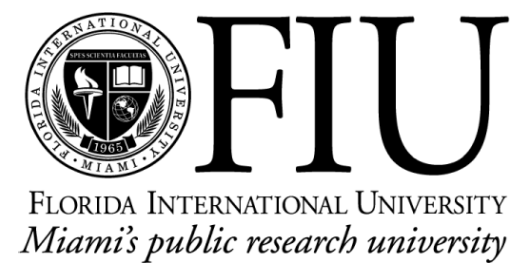

CONSENT TO PARTICIPATE IN A RESEARCH STUDY-ADULT

Title: Assessment of Nutritional Status of Patients on Hemodialysis: A Single Center Study from Jeddah, Saudi Arabia

The investigator of this study is Khadija Alharbi and she is a student at Florida International University (FIU). The investigator is looking at the prevalence of malnutrition among hemodialysis patients.

If you decide to be part of the study I will tell you what time I will evaluate your nutritional status. Your participation will require one hour of your time. During dialysis, the investigator will ask you general questions about your lifestyle and health, and then check your file for some laboratory values. After dialysis the investigator will measure weight, height, arm, and leg.

We do not expect any harm to you by being in the study. The assessment will not harm you in any way. By doing this study you will know your nutritional status and the study will provide a specific nutritional assessment protocol for Saudi dietitians' to apply.

Your information will be identified by a random number not your name. All your answers are private and will not be shared with anyone. Your data will be presented in the research result as a group. You may ask any questions about the study at any time. If you choose not to participate no other action is needed. You may also discontinue participation at any time without any penalty.

If you would like more information about this research after you are done, you can contact Dr Nabila Aqeel or me at 0504698455 . If you feel that you were mistreated or would like to talk with someone about rights as a volunteer in this study you may contact Dr. Patricia Price, the Chairperson of the FIU Institutional Review Board at 001-305-348-2494.

We appreciate your participation; your signature below indicates that all questions have been answered to your liking. You are aware of your rights and you would like to be in the study.

Signature of Participant

Printed Name

Date 
I have explained the research procedure, subject rights and answered questions asked by the participant. I have offered him/her a copy of this informed consent form.

Signature ofWitness

Date 


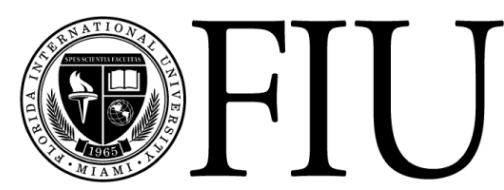

FLORIDA INTERNATIONAL UNIVERSITY

Miami's public research university

\section{بالغين -بحث دراسة في للذششاركة الموافقة}

\section{واحد مركز دراسة : الكلوي سيلالغ لمرضى التغذوية الححالة تقي يقم :العنوان

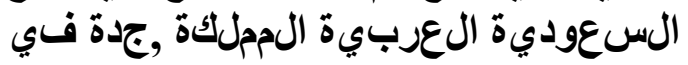

\section{الباحثة لمذه الدر اسة مي خدبجة الحربي وهي طالبة في جامعة فلوريديدا الدولبية. الباحثة

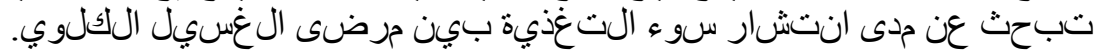

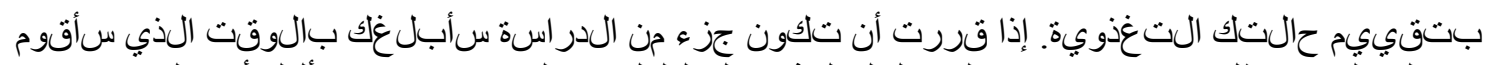

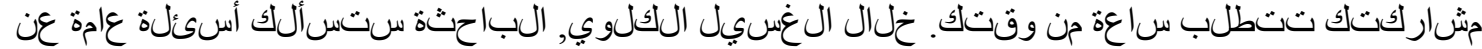

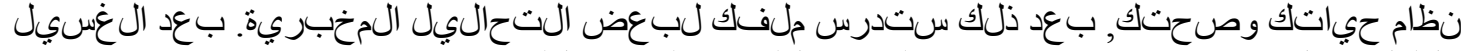

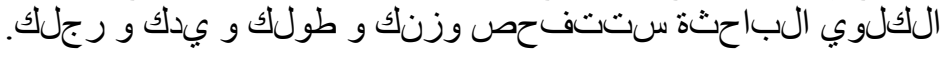

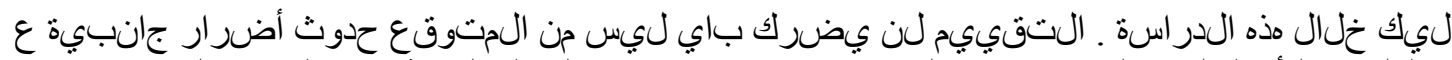

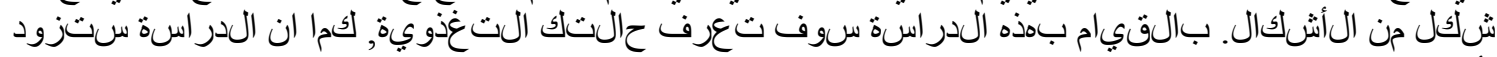

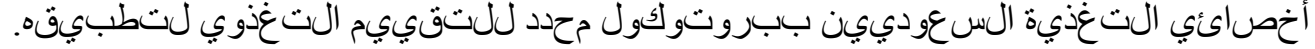

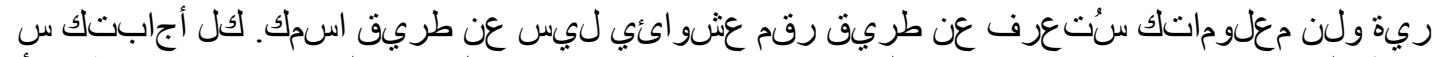

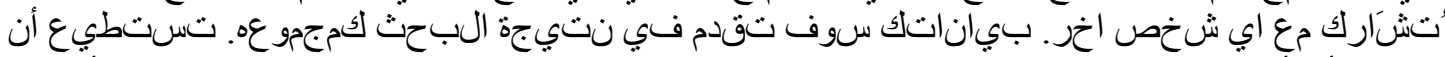

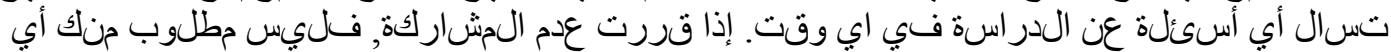

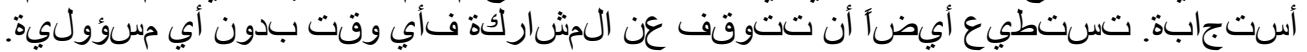

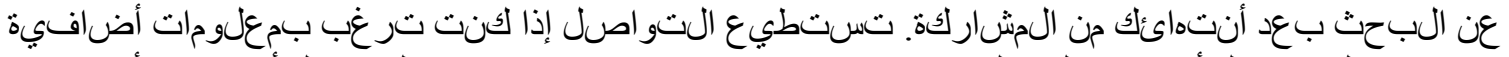

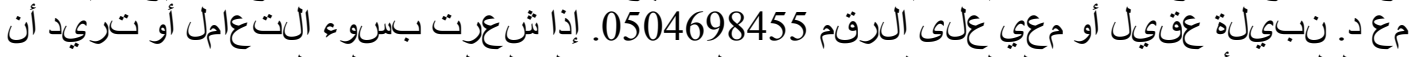

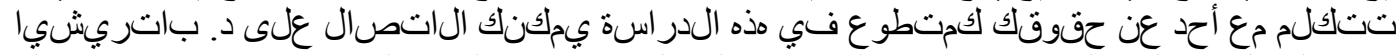

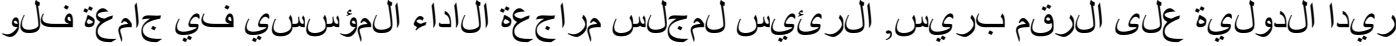




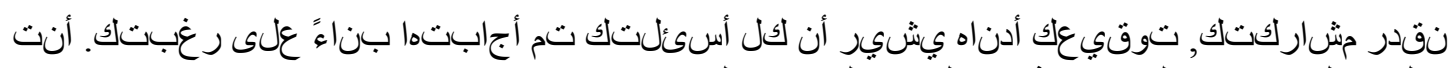

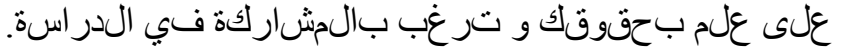

الأسم

التخاريخ

لقد فسرت إجراءات البحث و حقوق المشارك و إجابات السعثلة المطروحة من قبل المشارك. لقد

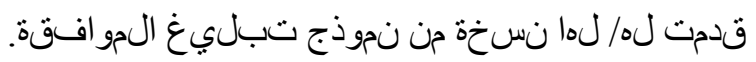

الت التاريخ 


\section{APPENDIX II}

\section{Questionnaires}

\section{Personal, Diet, and Health Questions}

2. Dialysis Diet and Fluid Non-Adherence

Questions 


\section{NUTRITIONAL STATUS OF HEMODIALYSIS PATIENTS \\ JEDDAH KIDNEY CENTER, JEDDAH, SAUDI ARABIA}

Patient's Number:

File Number:

Date:

\section{Personal, Diet, and Health Questions}

1. What is your gender? $\square$ Male $\square$ Female

2. What is your age?

$\square$ 18-24 years

$\square$ 25-34 years

$\square$ 35-44 years

$\square 45-54$ years

$\square$ 55-64 years

$\square 65$ years and over

3. Are you married?

$\square$ Yes

$\square$ No

4. Where do you reside?

$\square$ City

$\square$ Village

5. Is your residence?

$\square$ Owned

$\square$ Rent

$\square$ other 
6. What is your ndionality? $\square$ Saudi

Non-Saudi

\section{Personal, Diet, and Health Questions (continued)}

7. What is the highest level of education you have completed?

$\square$ None

$\square$ Elementary School

$\square$ Middle School

$\square$ High School

$\square$ Diploma

$\square$ Bachelor's Degree

$\square$ Master's Degree

๑ Doctoral Degree

$\square$ Post Doctoral

$\square$ Other (Please Specify)

8. Are you mployed?

$\square$ Yes

$\square \mathrm{Nb}$

a. If YES; in which employment sector do you work?

$\square$ Public

$\square$ Private

$\square$ Self

b. If NO; are you? 

$\square$ Student
$\square$ Retired
$\square$ Housewife
Unemployed

\section{Personal, Diet, and Health Questions (continued)}

9. What is your household income monthly?

$\square$ Less than 3000 Riyals

$\square$ 6000-10000 Riyals $\square 3000$ but less than 6000 Riyals

$\square$ More than 10000 Riyals

10. How many people live in your household including yourself?

$\square$ Less than 3 people

$\square$ 3-5 people

$\square$ more than

5 pøple

11. How many years you have had kidney disease?

$\square$ Less than a month $\square 1$ month but less than 6 months

$\square 6$ months but less than 1 year 
$\square 1$ year but less than 5 years $\square \quad 5$ years but less than 10 years $\quad \square 10$ years or more

12. How long you have been on hemodialysis?

$\square$ Less than a year $\square 1$ year but less than 5 years $\quad \square 5$ years but less than 10 years 1. Personal, Diet, and Health Questions (continued)

$\square 10$ years but less than 15 years $\square 15$ years but less than 20 years $\square 20$ years or more

13. What medication are you taking?

14. Do you suffer from other diseases in addition to chronic kidney disease? $\square$ Yes No

If YES; please specify?

15. Did the dietitian or the physician prescribed a diet for you? $\square$ Yes $\square$ No

16. Did the dietitian or the physician prescribed a fluid guidelines for you? $\square$ Yes No 


\section{$\underline{\text { 2. Dialysis Diet and Fluid Non-Adherence Questions }}$}

1. How many days during the past 14 days didn't you follow your diet guidelines?

2. To what degree did you deviate from your diet guidelines?

$\begin{array}{llcr}\text { No Deviation } & \text { Mild } & \text { Moderate } & \text { Severe } \\ \text { Very Severe } & & & \\ & & & \\ 0 & 1 & 2 & 3\end{array}$

3. How many days during the past 14 days didn't you follow your fluid guidelines?

4. How many days during the past 14 days didn't you follow your fluid diet? 


$\begin{array}{llll}\begin{array}{l}\text { No Deviation } \\ \text { Severe }\end{array} & \text { Mild } & \text { Moderate } & \text { Severe } \\ & & & \\ 0 & 1 & 2\end{array}$




\section{APPENDIX III}

\section{Anthropometric and Biochemical Data Collection Tool}




\section{NUTRITIONAL STATUS OF HEMODIALYSIS PATIENTS}

\section{JEDDAH KIDNEY CENTER, JEDDAH, SAUDI ARABIA}

\section{Anthropometrics Parameters}

Date

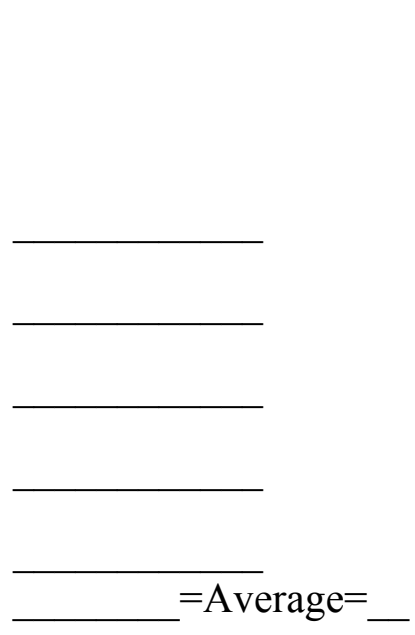

Body dy weight (day of sudy) =

Interdialytic weight gain:

Post dälysis weight pevious dälysis teatment $=$

Pre dalysis weight day of sudy $=$

Height $=$

$\mathrm{BMI}=$

$$
\mathrm{TSF}=
$$

$$
\mathrm{MAC}=
$$

$\mathrm{MAMC}=$

\section{Biochemical Parameters:}

Date

Albumin $=$ 


\section{APPENDIX IV}

Baxter Dietary Intake Spreadsheet 


\begin{tabular}{|c|c|c|c|c|c|}
\hline Food/Food Group & Serving & Estimate & $\begin{array}{l}\# \\
\text { Servs. }\end{array}$ & Kcal & Pro \\
\hline \multicolumn{6}{|l|}{ Beverages } \\
\hline Alcohol & $1.5 \mathrm{oz}$ or jigger & 1 jigger & 0 & 0 & 0 \\
\hline Beer & $12 \mathrm{oz}$. or 1 can & 1 can & 0 & 0 & 0 \\
\hline Coffee/Tea & 1 cup & Small Styrofoam cup & 0 & 0 & 0 \\
\hline Milk Sub/cream & $1 / 2$ cup & $\begin{array}{l}\text { Cupcake } \\
\text { wrapper } \\
\text { full }\end{array}$ & 0 & 0 & 0 \\
\hline Milk, 2\% & $1 / 2$ cup & $\begin{array}{l}\text { Cupcake } \\
\text { wrapper } \\
\text { full }\end{array}$ & 0 & 0 & 0 \\
\hline Milk, skim & $1 / 2$ cup & Cupcake wrapper full & 0 & 0 & 0 \\
\hline Milk, Whole & $1 / 2$ cup & Cupcake wrapper full & 0 & 0 & 0 \\
\hline Soda/Lemonade (Not low calorie or diet) & 1 cup or $2 / 3$ can & Small Styrofoam cup & 0 & 0 & 0 \\
\hline Wine & 4 oz. or $1 / 2$ cup & $\begin{array}{l}\text { Small juice or wine } \\
\text { glass }\end{array}$ & 0 & 0 & 0 \\
\hline \multicolumn{6}{|l|}{ Meat/Protein Sources } \\
\hline \multirow[t]{2}{*}{ Meat (Beef, Lamb, Chicken, Pork, etc) } & $1 \mathrm{oz}$ & Match box, thumb; & 0 & 0 & 0 \\
\hline & $3 \mathrm{oz}$ & Size of woman's palm & 0 & 0 & 0 \\
\hline $\begin{array}{l}\text { Wild Game Meat (Venison, Bear, Elk, Moose, } \\
\text { Rabbit, etc.) }\end{array}$ & $3 \mathrm{oz}$ & Size of woman's palm & 0 & 0 & 0 \\
\hline $\begin{array}{l}\text { Fish, fresh or canned (Tuna, Salmon, White } \\
\text { Fish, etc.) }\end{array}$ & 1 oz. or $1 / 4$ cup & & 0 & 0 & 0 \\
\hline Whole fillet & $5 \mathrm{oz}$ & 6" strip & 0 & 0 & 0 \\
\hline Dried fish & $1 \mathrm{oz}$ & & 0 & 0 & 0 \\
\hline $\begin{array}{l}\text { Seafood } \\
\text { (Prawn/Scallop/Oyster/Mussel/Cockle/Pipi, Paua) }\end{array}$ & $1 \mathrm{oz}$ & $\begin{array}{l}\text { Large shrimp or } \\
\text { scallop }\end{array}$ & 0 & 0 & 0 \\
\hline Egg & 1 large & & 0 & 0 & 0 \\
\hline Cheese & $1 \mathrm{oz}$ & $\begin{array}{l}\text { Pointer finger or } 3 \\
\text { dice }\end{array}$ & 0 & 0 & 0 \\
\hline Nuts & $1 \mathrm{oz}$ & Small handful & 0 & 0 & 0 \\
\hline Nut Butter & 1 Tbsp & $1 / 2$ ping pong ball & 0 & 0 & 0 \\
\hline Beans/Lentils & 1 cup & Man's Fist & 0 & 0 & 0 \\
\hline
\end{tabular}




\begin{tabular}{|c|c|c|c|c|c|}
\hline Soybean Curd/Tofu & $1 / 2$ cup & $\begin{array}{l}\text { Tennis ball or light } \\
\text { bulb }\end{array}$ & 0 & 0 & 0 \\
\hline \multicolumn{6}{|l|}{ Starch/Starchy Vegetables } \\
\hline Breads/Rolls/Bagel & 1 slice & & 0 & 0 & 0 \\
\hline Cereal, Cold (Oats, corn, rice, wheat) & 1 cup & Man's Fist & 0 & 0 & 0 \\
\hline $\begin{array}{l}\text { Chips/Crackers (tortilla/potato/saltines/cheese } \\
\text { crackers, etc.) }\end{array}$ & $1 \mathrm{oz}$. & $\begin{array}{l}\text { Handful, } \quad 5 \quad \text { saltine } \\
\text { squares }\end{array}$ & 0 & 0 & 0 \\
\hline Rice/Pasta/Hot Cereal & $1 / 2$ cup & $\begin{array}{l}\text { Tennis ball or light } \\
\text { bulb }\end{array}$ & 0 & 0 & 0 \\
\hline \multicolumn{6}{|l|}{ Vegetables } \\
\hline $\begin{array}{l}\text { Green/Yellow (Green beans, Spinach, lettuce, } \\
\text { etc.) }\end{array}$ & $1 / 2$ cup & $1 / 2$ fist or Light Bulb & 0 & 0 & 0 \\
\hline $\begin{array}{l}\text { Starchy } \\
\text { (Potato/Taro/Kamura/Corn/Squash) }\end{array}$ & $1 / 2$ cup & Hockey puck size & 0 & 0 & 0 \\
\hline $\begin{array}{c}\text { Fresh } \\
\text { (Orange/peach/kiwi/pear/feijoa/passion fruit/etc.) }\end{array}$ & $1 / 2$ cup & $\begin{array}{l}\text { Tennis ball or Light } \\
\text { Bulb }\end{array}$ & 0 & 0 & 0 \\
\hline Canned, sweetened & $1 / 2$ cup & $\begin{array}{l}\text { Tennis ball or Light } \\
\text { Bulb }\end{array}$ & 0 & 0 & 0 \\
\hline \multicolumn{6}{|c|}{ 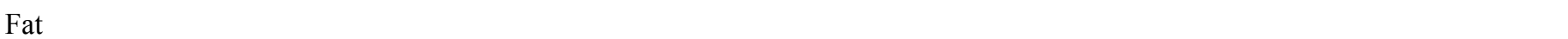 } \\
\hline Margarine, Butter & $1 \mathrm{tsp}$ & $\begin{array}{l}\text { Tip of finger or } \\
\text { quarter }\end{array}$ & 0 & 0 & 0 \\
\hline Oils, Salad Dressing & 1 Tbsp & 2 tea bags & 0 & 0 & 0 \\
\hline Mayonnaise/Creamy Salad Dressings & 1 Tbsp & $1 / 2$ ping pong ball & 0 & 0 & 0 \\
\hline \multicolumn{6}{|l|}{ Misc/Candy/Sugar } \\
\hline Hard Candy/Jelly Beans/Gum Drops & $1 \mathrm{oz}$ & Small handful & 0 & 0 & 0 \\
\hline Sugar & 1 tsp & $\begin{array}{l}\text { Tip of finger or } \\
\text { quarter }\end{array}$ & 0 & 0 & 0 \\
\hline Chocolate & $1 \mathrm{oz}$ & Size of domino & 0 & 0 & 0 \\
\hline Soup & & & & & \\
\hline $\begin{array}{l}\text { Broth Based Soup/Gruel (Chicken Noodle, } \\
\text { Onion, Veg Beef, etc.) }\end{array}$ & 1 cup & Small Styrofoam cup & 0 & 0 & 0 \\
\hline $\begin{array}{l}\text { Cream Based Soup (Cream of Mushroom, } \\
\text { Cream of Chicken, etc.) } \\
\text { Dessert }\end{array}$ & 1 cup & Small Styrofoam cup & 0 & 0 & 0 \\
\hline Cookies/Doughnut & 2 small & 1 small doughnut & 0 & 0 & 0 \\
\hline Ice Cream/Sherbet (Vanilla, Chocolate, Hokey & 1 cup & Size of man's fist & 0 & 0 & 0 \\
\hline
\end{tabular}




\begin{tabular}{|c|c|c|c|c|c|}
\hline \multicolumn{6}{|l|}{ Pokey) } \\
\hline Pudding/Pavlova & 1 cup & Size of man's fist & 0 & 0 & 0 \\
\hline \multicolumn{6}{|l|}{ Fast Food/Take Away } \\
\hline Fish Sandwich & 1 sandwich & & 0 & 0 & 0 \\
\hline Hamburger & 1 single & & 0 & 0 & 0 \\
\hline Hamburger & 1 double & & 0 & 0 & 0 \\
\hline Hot Dog & $1 \mathrm{w} / \mathrm{bun}$ & & 0 & 0 & 0 \\
\hline Milkshake & 1 cup & & 0 & 0 & 0 \\
\hline Pizza & 1 slice & $1 / 8$ th $16^{\prime \prime}$ & 0 & 0 & 0 \\
\hline Sausage Roll & 1 roll & & 0 & 0 & 0 \\
\hline Submarine Sandwich & 1 turkey & $6 \mathrm{inch}$ & 0 & 0 & 0 \\
\hline Taco/Burrito & 1 beef & & 0 & 0 & 0 \\
\hline \multicolumn{6}{|l|}{ Mixed Dishes } \\
\hline Casserole & 1 cup & Fist & 0 & 0 & 0 \\
\hline Frozen Entrée & 1 Small Dinner & Small container & 0 & 0 & 0 \\
\hline Meat Pie (Ave of 23 commercial brands) & 1 Individual size & & 0 & 0 & 0 \\
\hline Stir Fry Meat/Vegetables & 1 cup & & 0 & 0 & 0 \\
\hline \multicolumn{6}{|l|}{ Miscellaneous } \\
\hline Vegemite/Marmite & $5 \mathrm{gm}$ & Tsp & 0 & 0 & 0 \\
\hline Total & & & & & \\
\hline
\end{tabular}




\section{APPENDIX V}

7- Point Subjective Global Assessment 


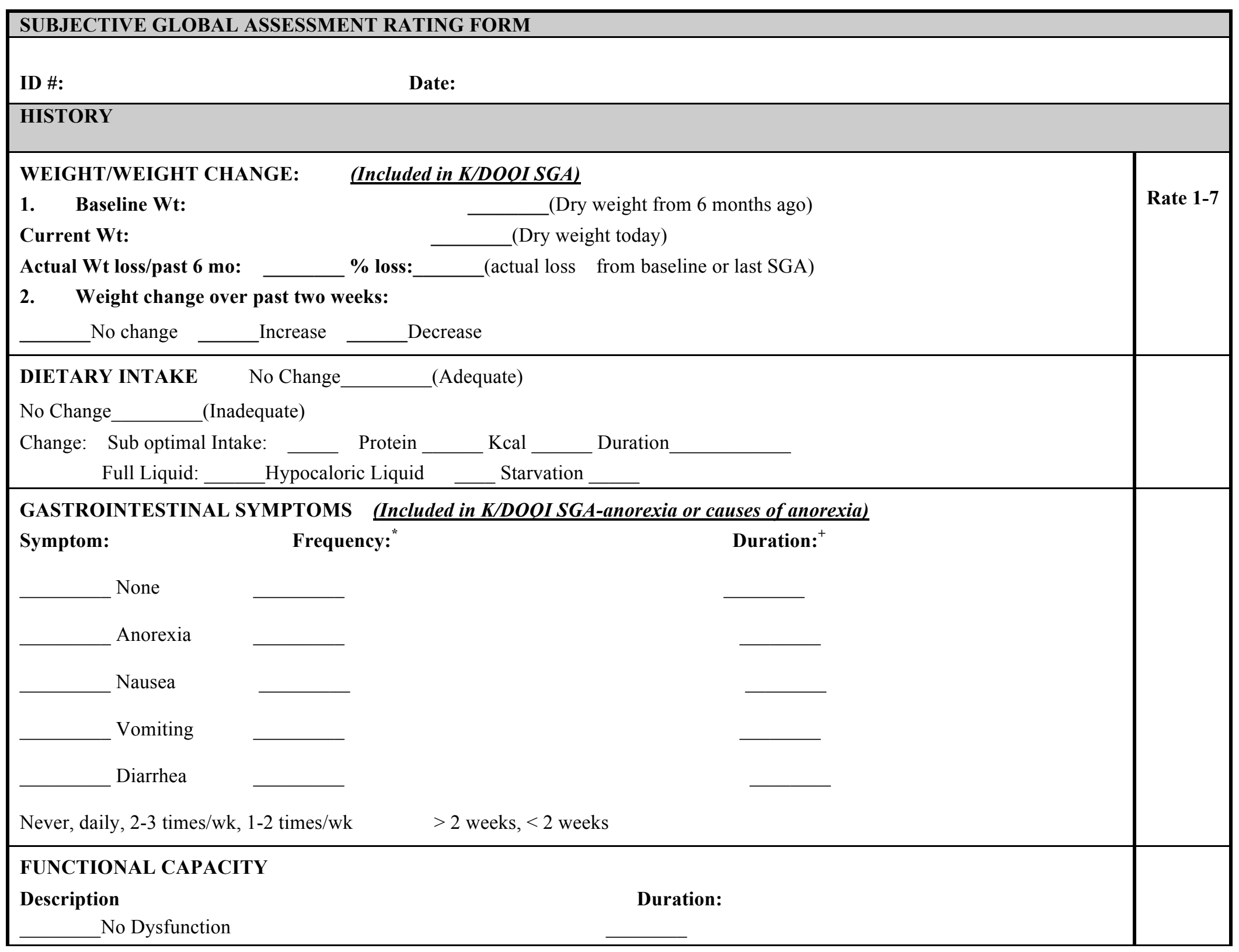




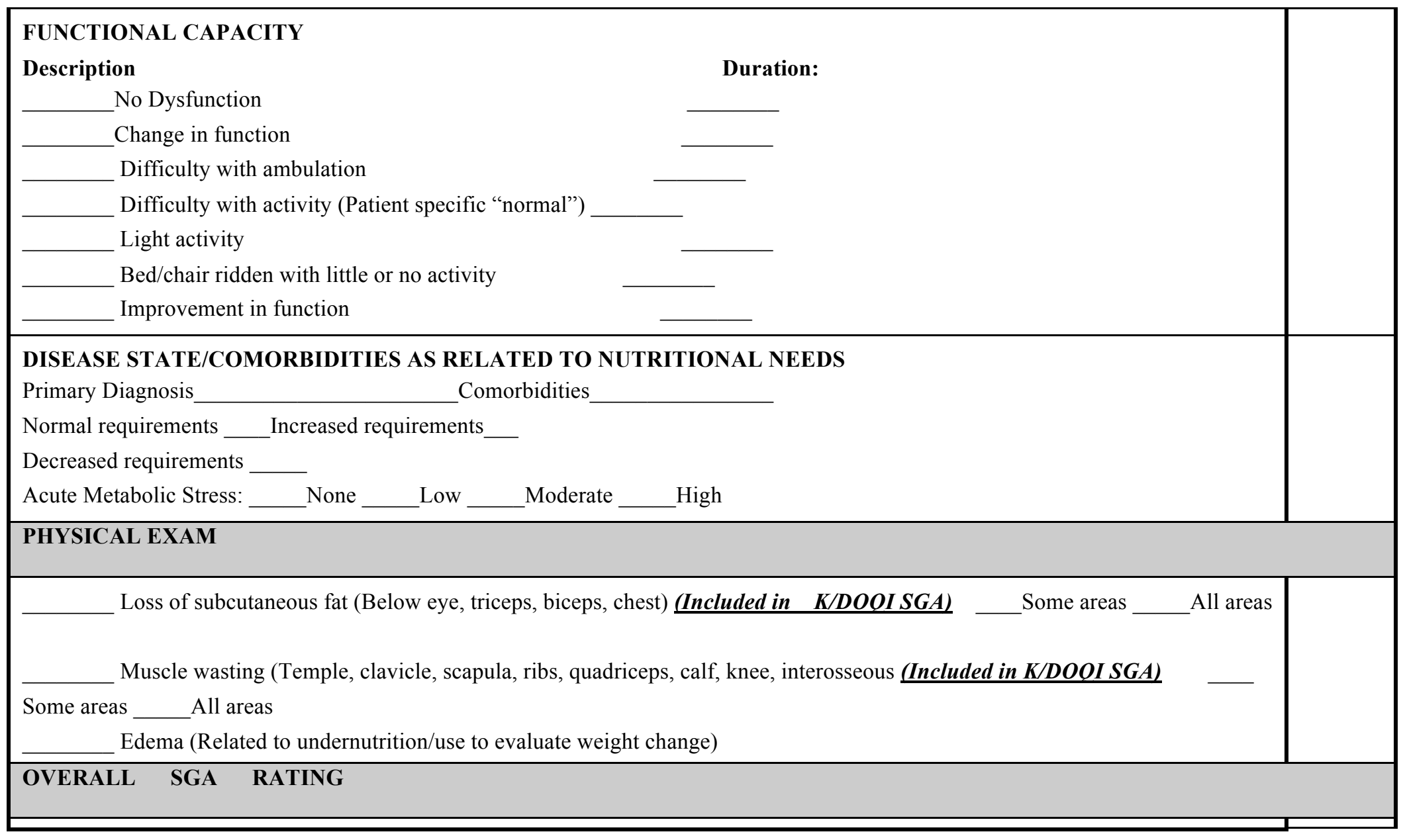

